Article

\title{
Experimental Validation of the Aerodynamic Performance of an Innovative Counter-Rotating Centrifugal Compressor
}

\author{
Cheikh Brahim Abed ${ }^{1,2,3, *}$, Sofiane Khelladi ${ }^{1} \mathbb{C}$, Michael Deligant ${ }^{1}\left(\mathbb{D}\right.$, Abdellatif El Marjani $^{2}$, Moisés Solis ${ }^{1}$ \\ and Farid Bakir ${ }^{1}$ (D) \\ 1 Arts et Métiers Institute of Technology, CNAM, LIFSE, HESAM University, 151 Boulevard de l'Hôpital, \\ 75013 Paris, France; sofiane.khelladi@ensam.eu (S.K.); Michael.DELIGANT@ensam.eu (M.D.); \\ moises.solis@ensam.eu (M.S.); Farid.BAKIR@ensam.eu (F.B.) \\ 2 EMISys, E3S Research Center, Mohammadia School of Engineers, Mohammed V University in Rabat, \\ Rabat BP 765, Morocco; elmarjani@emi.ac.ma \\ 3 Ecole Superieure Polytechnique, School of Engineering, Cite Cadres-Sebkha, Nouakchott BP 4303, Mauritania \\ * Correspondence: abedcheikhbrahim@gmail.com; Tel.: +33-767-315-5468
}

check for

updates

Citation: Abed, C.B.; Khelladi, S.; Deligant, M.; El Marjani, A.; Solis, M.; Bakir, F. Experimental Validation of the Aerodynamic Performance of an Innovative Counter-Rotating Centrifugal Compressor. Energies 2021, 14, 2582. https://doi.org/ $10.3390 /$ en14092582

Academic Editor: Alessandro Bianchini

Received: 19 March 2021

Accepted: 25 April 2021

Published: 30 April 2021

Publisher's Note: MDPI stays neutral with regard to jurisdictional claims in published maps and institutional affiliations.

Copyright: (c) 2021 by the authors. Licensee MDPI, Basel, Switzerland. This article is an open access article distributed under the terms and conditions of the Creative Commons Attribution (CC BY) license (https:/ / creativecommons.org/licenses/by/ $4.0 /)$.

\begin{abstract}
Turbomachinery with double counter-rotating impellers offers more degrees of freedom in the choice of design and control parameters compared to conventional machines. For these innovative machines, the literature review shows that more publications concerning axial type turbomachines are available than centrifugal ones. This work deals with a design and experimental performance analysis, applied to two counter-rotating impellers of a centrifugal compressor "CRCC". CRCC was designed with a specifically developed tool based on mean-line approach coupled with optimization algorithms and a stream-curvature through-flow method to satisfy the design criteria. This paper presents an experimental validation of the CRCC design tool and its performances against the baseline "SR", composed of one centrifugal impeller and a volute for which experimental data are available. CRCC numeric simulations are also validated by experimental data. For a fair comparison between CRCC and SR, the same volute is used for both configurations. The CRCC studied here includes a first conventional impeller with an axial inlet and a radial outlet, while the second impeller is parametrically designed and can be considered a rotating bladed diffuser with a radial inlet and outlet. The obtained results show that CRCC can deliver a pressure rise increase of two compared to SR, along with an increase of isentropic efficiency and also validate the design method of this novel layout. The experimental results also show that the speed ratio of CRCC has a positive effect on the surge and shock margin.
\end{abstract}

Keywords: aerodynamic; counter-rotating; centrifugal compressor; design validation; experimental; performance

\section{Introduction}

The idea of using CR machines goes back a long way. Already in 1825, a certain engineer named Jacob Perkins, and then in 1829, William Church, had imagined this solution for boat propellers [1]. Lesley [2] performed a first experimental study of these machines in 1933 on counter-rotating propellers. Since then, those machines have attracted great interest in the turbomachine application by their particular potential to improve performance over conventional ones by exploiting the counter swirl of the flow received by the downstream rotor. This is possible by recovering the flow from the upstream impeller and adding energy to it by turning the downstream impeller in the opposite direction. Therefore, this configuration should allow an increase of the head compared to its conventional counterpart in comparable sizes and gives an additional degree of freedom resulting from the second turning impeller.

Since then, a variety of studies focusing on this concept in axial machines have been carried out, showing their advantages over conventional ones. 
For the axial compressors, the work of Sharma et al. [3-6] has contributed to the study of CR machines in a single stage and shows their advantages compared to conventional ones in terms of pressure rise and gain in the stall margin by varying the speed ratio of the impellers and the axial gap between them. Since then, various studies have been carried out to understand the physical phenomena in those machines, such as the work of Gao et al. [7]. Dejour et al. [8] studied a non-axial CR compressor, which cannot be described as a CRCC because the outlet flow is in axial direction. However, this configuration provides, at a very low pressure ratio, an increase in pressure rise with almost no change in efficiency. However, their results are obtained only by CFD with no experimental validation.

Some investigations on CR axial fans have been carried out by Nouri et al. [9,10] and Wang et al. [11,12] at Arts et Métiers Sciences and Technology, HESAM University, showing the performance improvements of these machines compared to conventional ones. By modifying the speed ratio and the axial space between the two impellers, they get a wider operating range of efficiency with improvement of global performances. In the same way, Cao et al. [13-15] have also studied the CR axial pumps. They also reported an important improvement in performance.

Also, the work of Fukutomi et al. [16] in CR centrifugal fans shows that these machines can allow a significant increase of the head but with a meaningful drop in efficiency.

In the same way, CR axial pumps have been widely studied by Cao et al. [13-15] and others. They reported also an important improvement in performance similar to that of CR axial fans.

In a mixed-flow centrifugal pump configuration, the only work done, to the author's knowledge, on CR machines in centrifugal configuration are carried out by Tosin et al. [17]. They show a significant improvement in efficiency and power density given by CR machines compared with conventional ones by rotational speed ratio modulation. They also describe an accurate design method in which they adapt the second impeller to the first one while maximizing the total head.

Two patents presented by Price [18] and Friebe et al. [19] have been found, presenting the idea of using CR centrifugal impellers and employing gas as a working fluid. However, no information, to the author's knowledge, was supplied about the adopted design method nor performance investigations with those patents, and whether those machines were compressors or fans. This lack of information about those machines is the major motivator for the present study. Contrary to pumps, compressors operate with compressible flows, which leads to a limited performance range due to stall and chocking phenomena.

The research work carried out recently within the LIFSE laboratory seeks to show a better understanding of the operation and control of the sizing of centrifugal compressors with two counter-rotating rotors, never before studied in the open literature. We are seeking:

- $\quad$ to demonstrate their efficiency in terms of power density (good efficiency and compactness),

- to highlight their regulatory capacity,

- $\quad$ to limit the inconveniences caused by increased complexity (double drive motor). Indeed, in the counter-rotating compressor, the two rotors require two drive systems such as for example two electric motors, which increases the complexity of the system. However, the literature shows the existence of an adequate choice of an electric motor with induction employing two coaxial shafts developed specially for counter-rotating turbomachines as shown by the work of Kanemoto et al. [20] and Tosin et al. [17].

In this work, an experimental study of the aerodynamic performances of a CRCC is carried out along with numerical simulations on some working points of interests. Then, a comparison in performance is made between CRCC and SR, for which the same outlet radius of its impeller as that of the rear impeller of CRCC. The same volute is employed to simplify the study and gives a fair comparison between CRCC and SR. A brief description of the developing tools permitting the design of the both impellers of the CRCC is also presented. 


\section{Case Study}

At the LIFSE laboratory, a standard configuration of a centrifugal compressor composed of one impeller and a volute working in aspiration mode (called SR) has been designed and tested for a particular application, in which the compressor has to work with low mass flow rate. The SR is composed of one centrifugal impeller and a volute. Table 1 shows the main geometrical parameters of the SR impeller and Figure 1 show the experimental performance map of the SR at various rotational speeds with the desired design point for CRCC.

The aim of this study is to investigate, experimentally and numerically, by using the CRCC instead of the SR for the application mentioned below. The fundamental idea here is to make use of the additional degree of liberty given by the CRCC to highlight the gain in performances compared to the SR. The operating range of interest in the current study is shown in Figure 1.

Table 1. Geometrical parameters of the SR impeller.

\begin{tabular}{cc}
\hline Parameter & Value \\
\hline$r_{h 1}$ & $30 \mathrm{~mm}$ \\
$r_{h 1}$ & $30 \mathrm{~mm}$ \\
$r_{s 1}$ & $81 \mathrm{~mm}$ \\
$r_{2}$ & 143 \\
$\beta_{b h 1}$ & $-50^{\circ}$ \\
$\beta_{b s 1}$ & $-52^{\circ}$ \\
$\beta_{b 2}$ & $-63^{\circ}$ \\
$b_{2}$ & $30 \mathrm{~mm}$ \\
$Z_{I}$ & $7 / 7$ \\
$\dot{m}_{\text {design }}$ & $0.75 \mathrm{~kg} \cdot \mathrm{s}^{-1}$ \\
$N_{S R}$ & $13 \mathrm{kRPM}$ \\
\hline
\end{tabular}

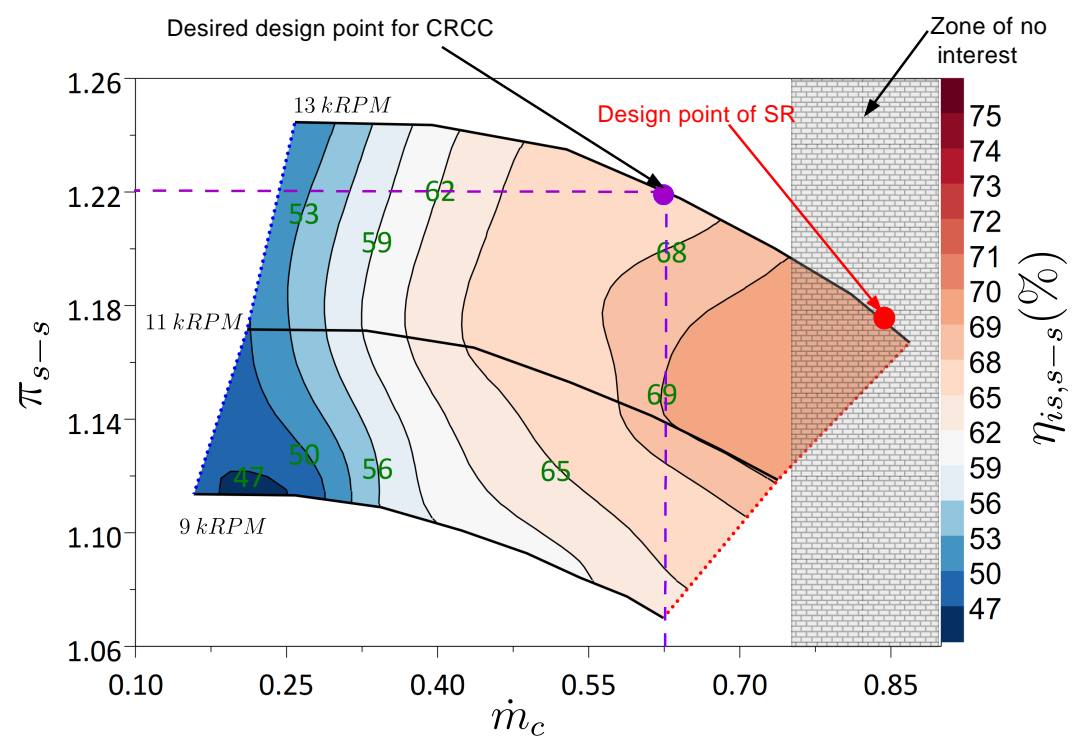

Figure 1. Performance map of the baseline with its design point and the desired design point for CRCC. 


\section{Design Method of the Innovative CRCC Configuration}

A specific tool named C3Design based on mean-line approach, 2.5D through-flow solver and some optimization algorithms are developed for the current study in order to design CRCC. This tool can also design conventional configurations and reproducing existing ones if the detail of geometric parameters and blades angle distribution are known. If it's not the case, it can calculate those parameters based on the well-known design practice rules of turbomachines as those given in Reference [21]. The main geometrical parameters permitting the design of CRCC are given in Figure 2 and their velocity triangles are presented in Figure 3.

C3Design is developed from the same perspective as the design code of axial turbomachines MFT and 3DTurbo, the last upgrade of HELIOX [22,23] employed for the design of centrifugal pumps in LIFSE laboratory. MFT was employed to design conventional and CR axial fans by Nouri et al. [9,10] and Wang et al. [11,12]. It was also coupled with optimization techniques to improve the design of axial pumps by Ait chick et al. [24,25].

C3Design was also used to optimize the performance of turbocharger compressors as shown in Reference [26].

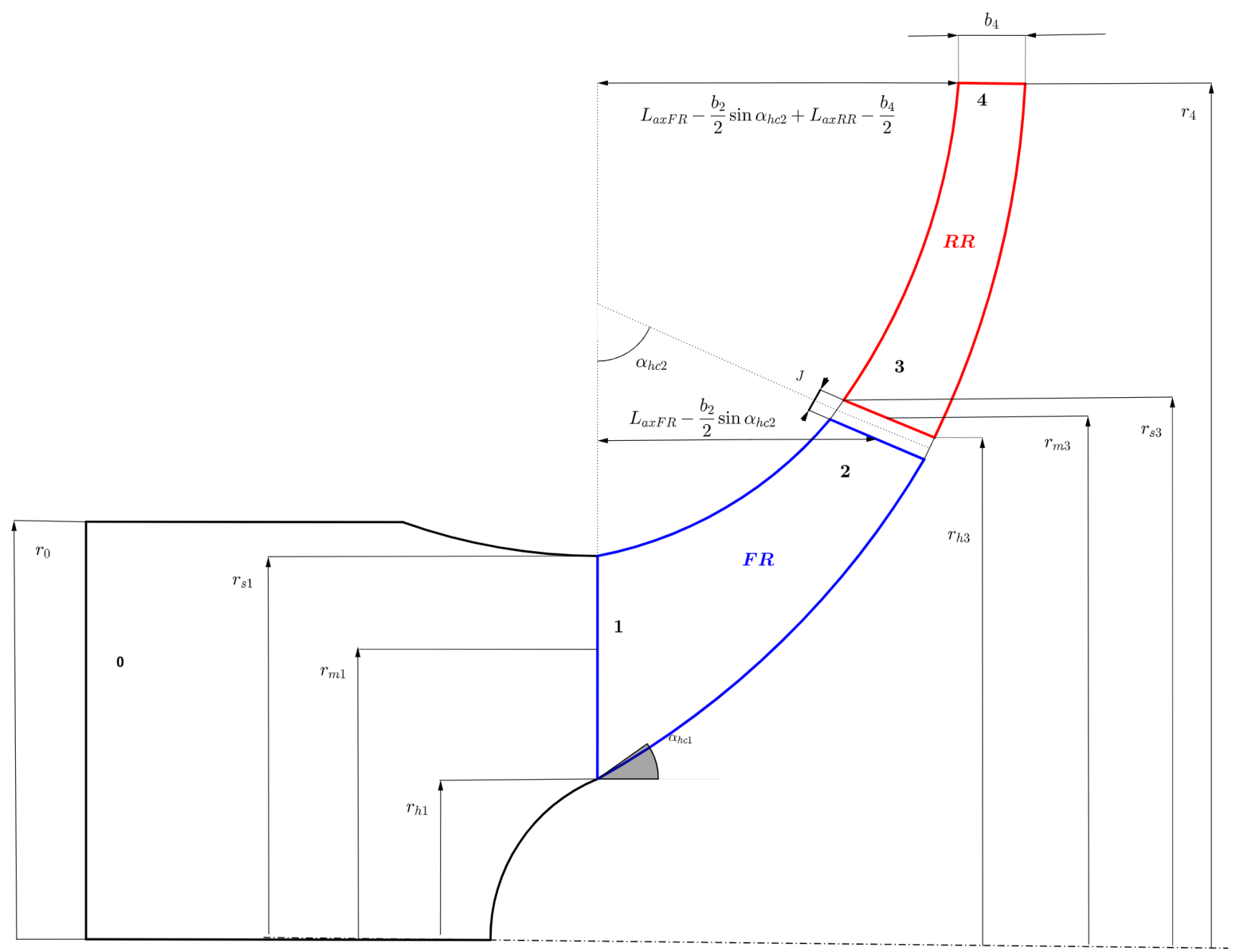

Figure 2. CRCC geometrical design parameters. 


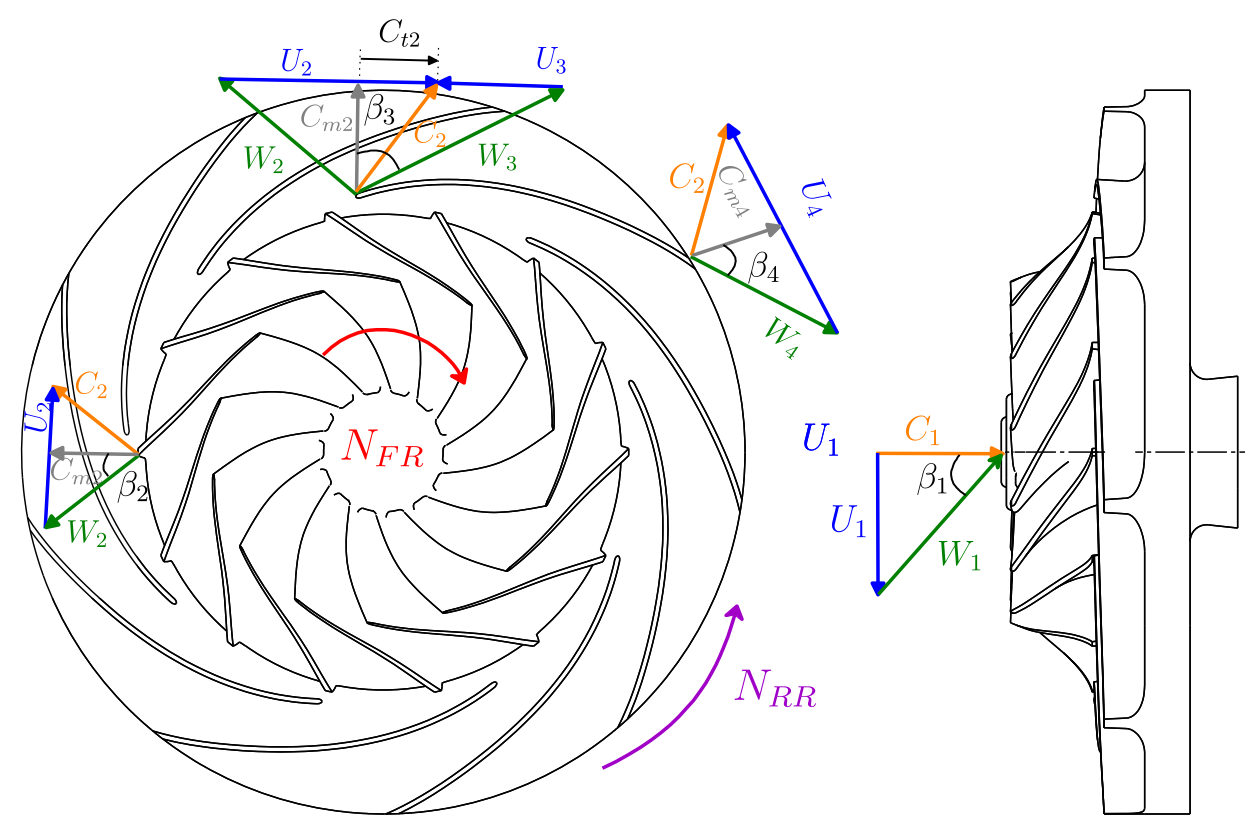

Figure 3. Ideal CRCC velocity triangles.

\subsection{Velocity Triangles}

The CRCC is composed of two successive impellers, the front impeller is called the FR, while the rear impeller is the RR.

The velocity triangles of the FR are similar to that of the SR impeller. However, the inlet velocity triangles of the RR are particular because of the strong negative counter swirl at its inlet. This affects the design procedure for the RR. Figure 3 shows the different velocity triangles from the inlet to the outlet of $\mathrm{CR}$ machines.

For mechanical operating considerations, a small radial gap between the FR and the $\mathrm{RR}, J=3 \mathrm{~mm}$ is considered for the design of CRCC. It was therefore assumed that no change in velocity fields from the outlet of FR to the inlet of RR during the design phase of CRCC:

$$
C_{2}=C_{3}, C_{t 2}=C_{t 3}, C_{m 2}=C_{m 3} .
$$

The tangential component of absolute velocity at the outlet of FR, $C_{t 2}$, contributes to the increase of the tangential component of the relative velocity at the inlet of $R R$ impeller as:

$$
W_{t 3}=U_{3}+C_{t 3} .
$$

Equation (2) shows how the relative velocity at the inlet of the RR dramatically increases with the CR effect. This can lead to transonic or sonic inlet conditions, even if the peripheral speed of the RR remains small.

\subsection{Comparison between $C R C C$ and SR Layout}

In this study, and for a reasonable comparison of the enthalpy generated by CRCC and SR configurations, the impeller outlet diameter and rotational speed of the RR and that for the SR impeller, are kept the same. By observing the ideal representation of velocity triangles in Figure 3 and using Euler's formulas for turbomachines [27] given in Equation (3), one can see the advantage of CRCC compared to the SR.

According to the assumptions introduced above, we have $U_{2 S R}=U_{4 R R}$, since the SR impeller and the RR have both the same outer diameter and rotational speed and by assuming no pre-swirl at the inlet suction of CRCC and SR, Equations (4)-(7) show the head rise produced by the SR and CRCC in terms of enthalpy (taking as positive direction that of the rotation of RR).

$$
\Delta h_{S R}=U_{2 S R} \times C_{t 2 S R}
$$




$$
\begin{gathered}
\Delta h_{C R}=\Delta h_{F R}+\Delta h_{R R} \\
\Delta h_{F R}=\left(-U_{2}\right) \times\left(-C_{t 2}\right)=U_{2} \times C_{t 2} \\
\Delta h_{R R}=U_{4} \times C_{t 5}-U_{3} \times C_{t 3} \approx U_{4} \times C_{t 5}-\left(U_{3} \times\left(-C_{t 2}\right)\right) \\
\Delta h_{R R} \approx U_{4} \times C_{t 5}+U_{3} \times C_{t 2} \\
\Delta h_{C R} \approx U_{4} \times C_{t 5}+\left(U_{3}+U_{2}\right) \times C_{t 2} .
\end{gathered}
$$

The essential benefit in terms of head rise is highlighted by the positive sign of the second term of the Equation (7), which leads to an increase of the RR enthalpy. The total enthalpy rise generated by the CR machine is given by Equation (8). However, observing Equation (1), the principal disadvantage of CRCC configuration represents the high relative velocity at the RR leading edge. At off-design conditions, if a high incidence occurs combined with high relative velocity, it might cause a significant drop of the pressure on the RR suction side, inducing stall phenomena. However, the additional degree of freedom given by CRCC may reduce this large flow deviation from the RR leading edge.

\subsection{The Obtained FR and RR Impellers of $C R C C$}

A CRCC configuration is designed using C3Design and manufactured in order to be tested at the LIFSE laboratory. The complete design methodology of this configuration can be found in Reference [28], in which an adapted volute is used for CRCC. However, in this study, the same volute of the SR is used for CRCC for the purposes of comparison. Figure 4 shows a 3D view of the manufactured SR impeller, while Figure 5 shows a 3D view of the manufactured FR and RR impellers. All the impellers in the present study were manufactured with a special aluminum alloy, and their fatigue resistance to various stresses has been already verified.

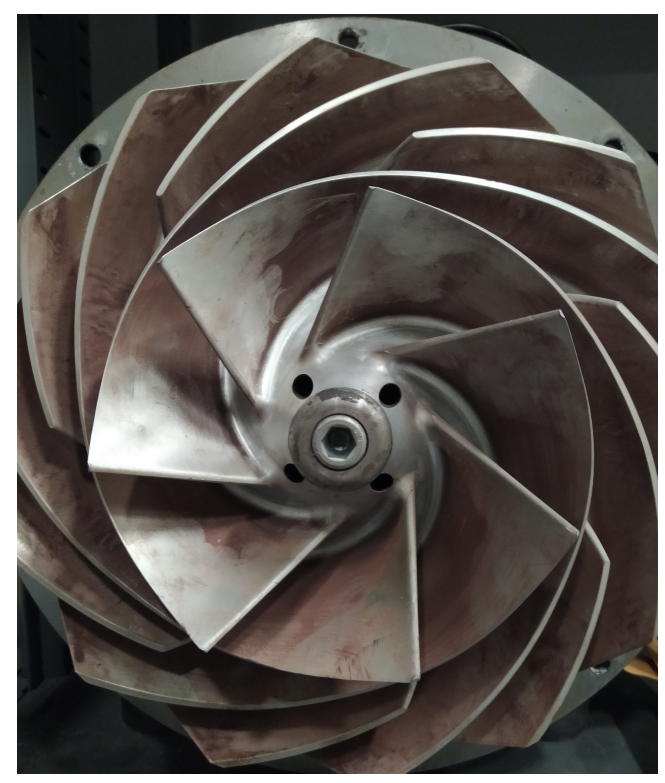

Figure 4. Manufactered SR impeller. 


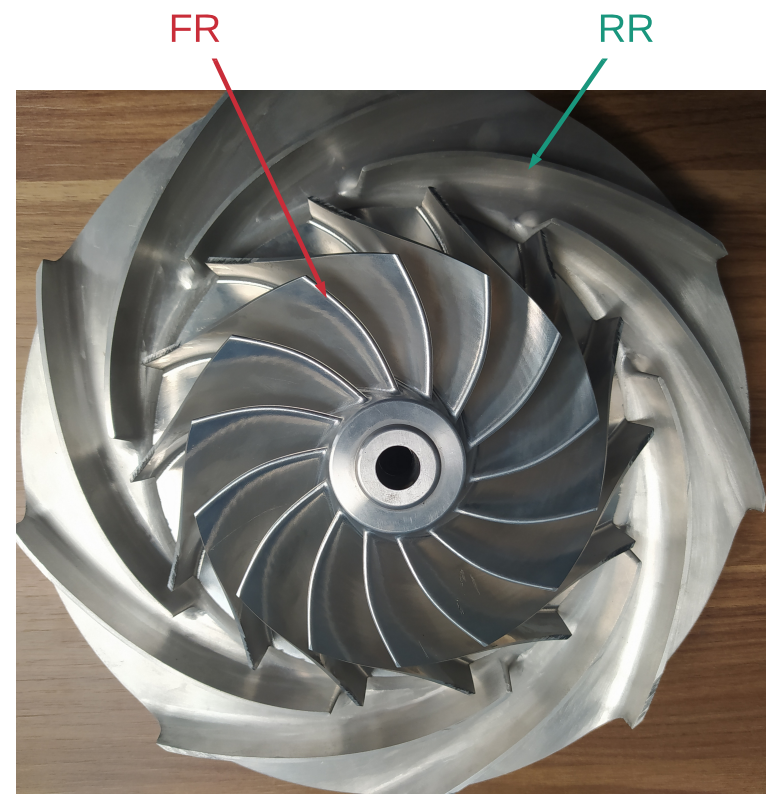

Figure 5. Manufactered FR and RR impellers.

The CRCC is designed to produce a static to static pressure ration of 1.42 at design conditions: $\dot{m}_{c}=0.63 \mathrm{~kg} \cdot \mathrm{s}^{-1}, N_{F R}=17 \mathrm{kRPM}$ and $N_{F R}=13 \mathrm{kRPM}$. Figures 6 and 7 show, respectively, the dimensionless blade surface relative velocities $W_{d}$ of FR and RR impellers at design conditions. These blade surface velocities confirm that the design of FR and RR impellers align with the good design practice of turbomachines in which these velocities should decrease moderately from inlet to outlet at the shroud. At the hub, a decrease and then a moderate increase of velocity must be obtained to avoid large flow separation for conventional impellers (case of FR) [29,30]. As for the RR impeller, which is almost a purely radial impeller, the blade surface velocities are almost identical for both hub and shroud surfaces. Indeed, no velocity gradient is present between hub and shroud surfaces. This indicates that the design of the RR impeller is actually better than the FR impeller because of its meridian shape (purely radial).

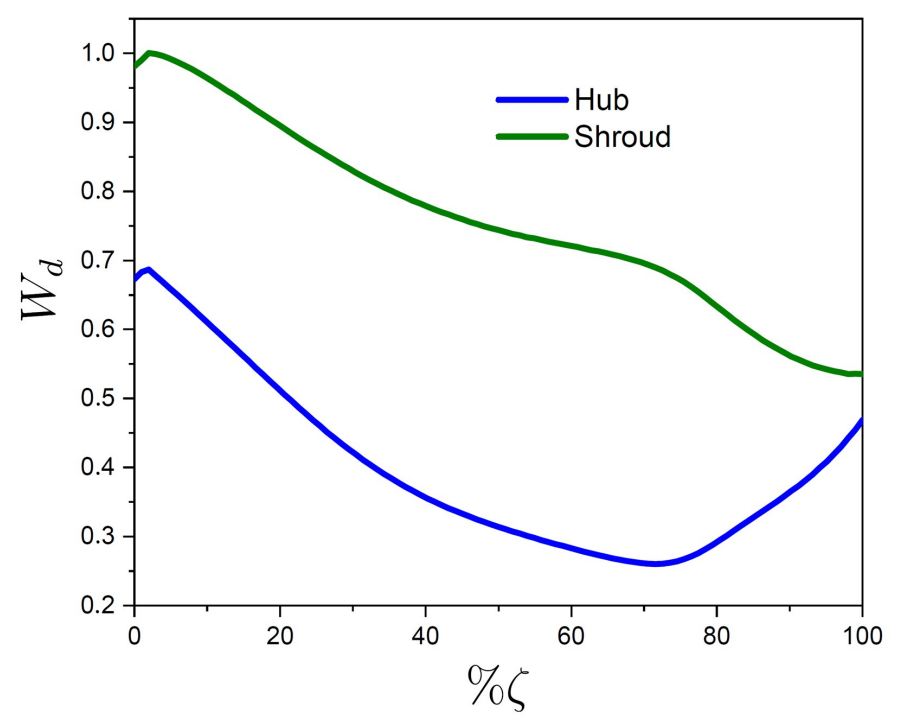

Figure 6. Dimensionless blade surface relative velocities of FR at hub and shroud calculated by the design code. 


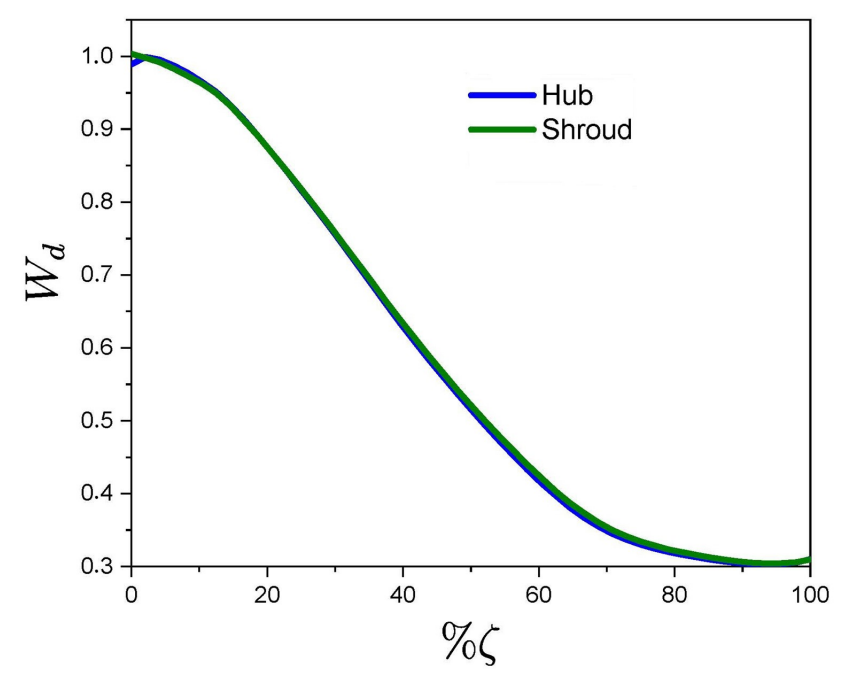

Figure 7. Dimensionless blade surface relative velocities of RR at hub and shroud calculated by the design code.

The meridian shape of the CRCC impellers resulting from calculations is smaller by half compared to the SR impeller, as shown by Figure 8. This is caused by the fact that the CRCC is designed to work with a design mass flow rate smaller than that of the SR $\left(\dot{m}_{\text {design }}=0.75 \mathrm{~kg} \cdot \mathrm{s}^{-1}\right.$ for SR at a speed of $N_{S R}=13 \mathrm{kRPM}$ and $\dot{m}_{\text {design }}=0.55 \mathrm{~kg} \cdot \mathrm{s}^{-1}$ at $N_{F R}=17 \mathrm{kRPM}$ and $N_{R R}=13 \mathrm{kRPM}$ for CRCC).

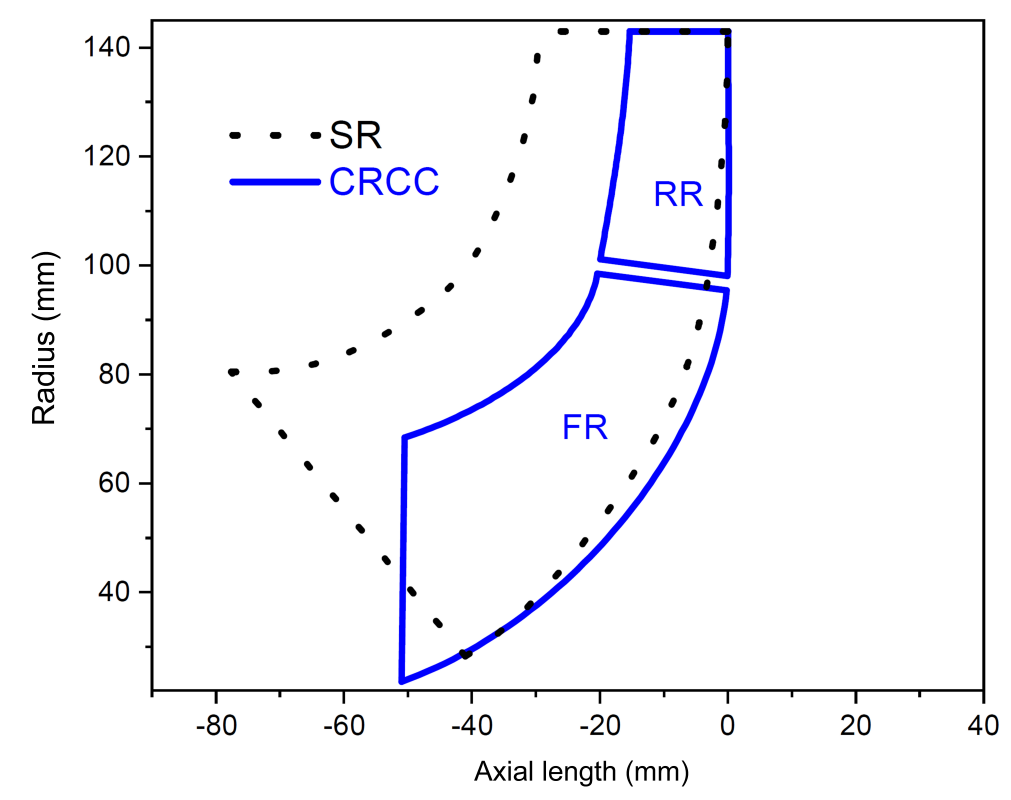

Figure 8. Meridional shape comparaison between CRCC and SR impellers.

\section{Numerical Method}

The numerical calculations were carried out using a computational fluid dynamic code, which is based on the finite volume method. The commercial software STAR-CCM+ [31] was used. Steady simulations were conducted for performance evaluation and flow field analysis. A coupled solver (Density based solver) was used because it is more suitable for highly compressible flow with high Mach number but expensive in terms of computational resources [31]. It solves the conservation equations for momentum, energy and continuity simultaneously as a vector of equations. The coupled flow was modeled at second order 
discretization with implicit integration. The fluid domain contained an inlet pipe, an elbow connected directly to FR, FR, RR, volute and an outlet pipe as shown by Figure 9. The boundary conditions were set at the same position of the actual sensors of the test rig. The inlet boundary condition was specified as constant mass flow and at the outlet, a static pressure was specified equal to the atmospheric pressure. These conditions are actually the same conditions of the measurement. In this study, frozen-interface was adopted for all simulations. A moving reference frame was used to account for the relative motion between the elbow, FR, RR and the volute. The fluid domain mesh was polyhedral, with a refined boundary layer mesh on the blades, interfaces and walls as shown by Figure 10 .

The $k-\omega$ SST model for turbulence was used with an automatic wall function [31]. In fact, it was observed that this turbulence model captures better the flow behavior in adverse pressure gradients and flow separation [32,33]. The work of Bourgeois et al. [34] highlights that the $k-\omega$ SST model is the most advantageous compared to other turbulence models, in terms of accuracy. The maximum value of $y+$ is below two for the entire model as shown by Figure 11. After a mesh sensitivity study on the static-to-static pressure ration and corresponding isentropic efficiency shown by the Table 2, the global number of elements is almost 12 millions.

Table 2. Mesh sensitivity study at the design point.

\begin{tabular}{ccccc}
\hline No of Elements (In Millions) & $\pi_{\boldsymbol{s}-\boldsymbol{s}}$ & Error of $\boldsymbol{\pi}_{\boldsymbol{s}-\boldsymbol{s}} \mathbf{( \% )}$ & $\boldsymbol{\eta}_{\boldsymbol{s}-\boldsymbol{s}} \mathbf{( \% )}$ & Error of $\eta_{\boldsymbol{s}-\boldsymbol{s}} \mathbf{( \% )}$ \\
\hline 1.185 & 1.343 & 6.065 & 80.132 & 4.337 \\
5.689 & 1.406 & 1.660 & 78.736 & 2.520 \\
7.094 & 1.412 & 1.227 & 77.675 & 1.131 \\
11.978 & 1.420 & 0.722 & 77.051 & 0.324 \\
53.459 & 1.430 & - & 76.801 & - \\
\hline
\end{tabular}

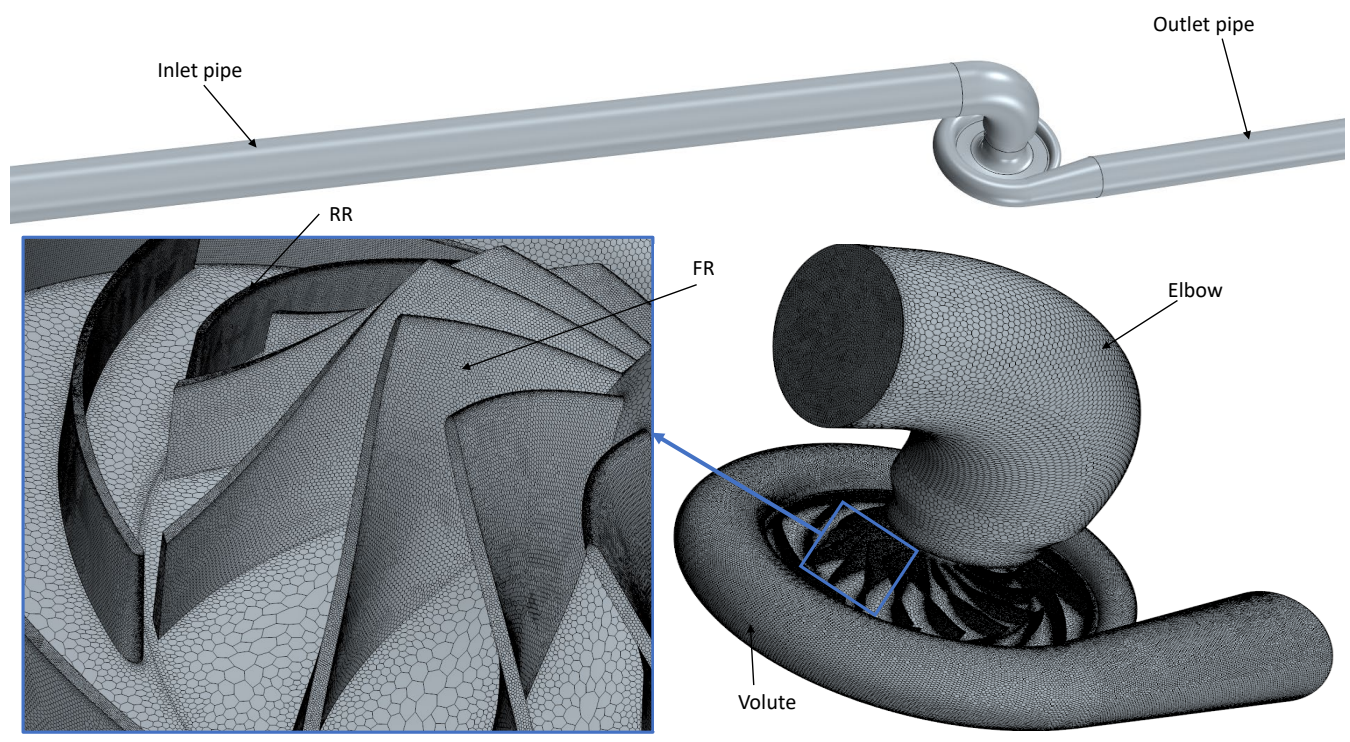

Figure 9. Three-dimensional model for the simulation and corresponding mesh. 


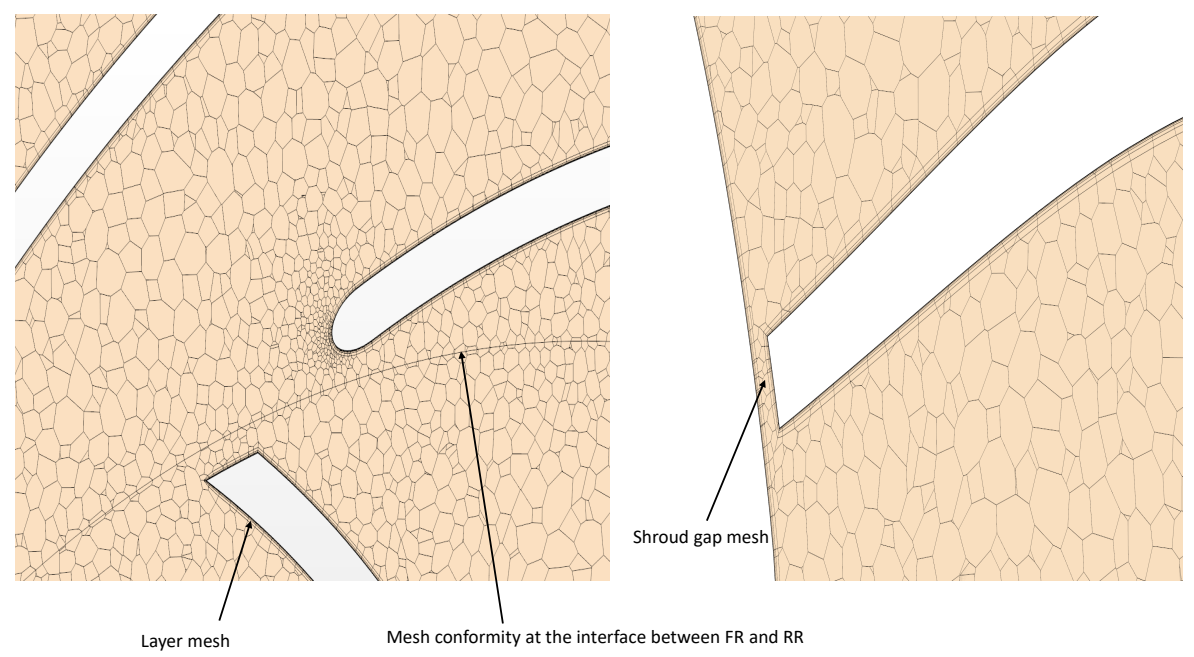

Figure 10. Detailed mesh of the 3D model.
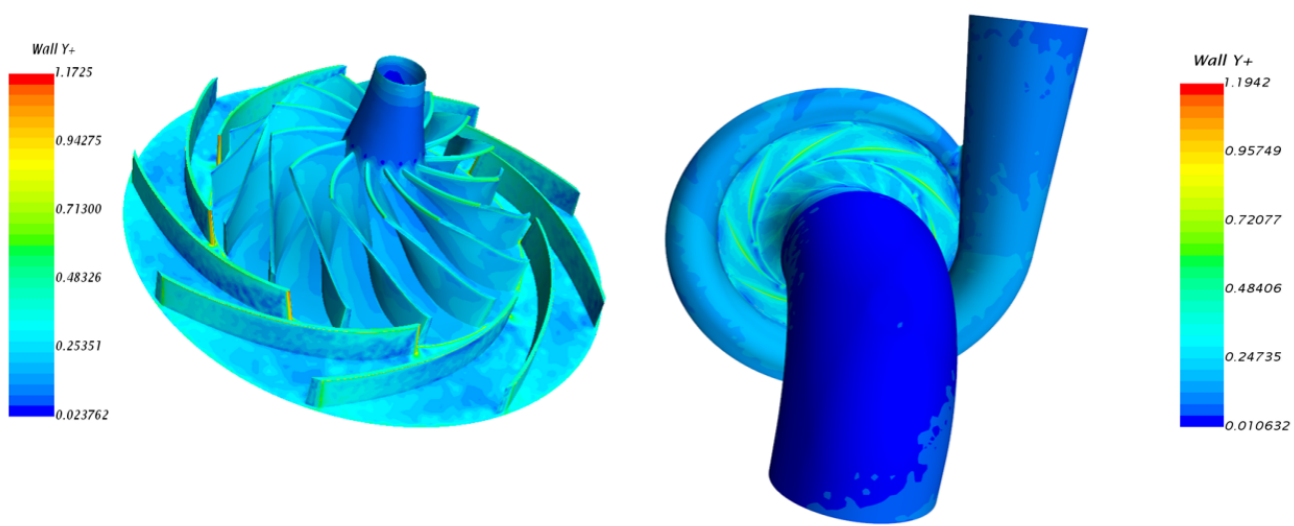

Figure 11. $y+$ distribution on wall surfaces of the fluid domain.

\section{Experimental Setup}

5.1. Description of the Test Rig

A test rig working in suction application was built at the LIFSE laboratory to experimentally investigate the aerodynamic performances of CRCC, which is shown in Figure 12. A previous version of this test rig was used before for the study of SR performance.

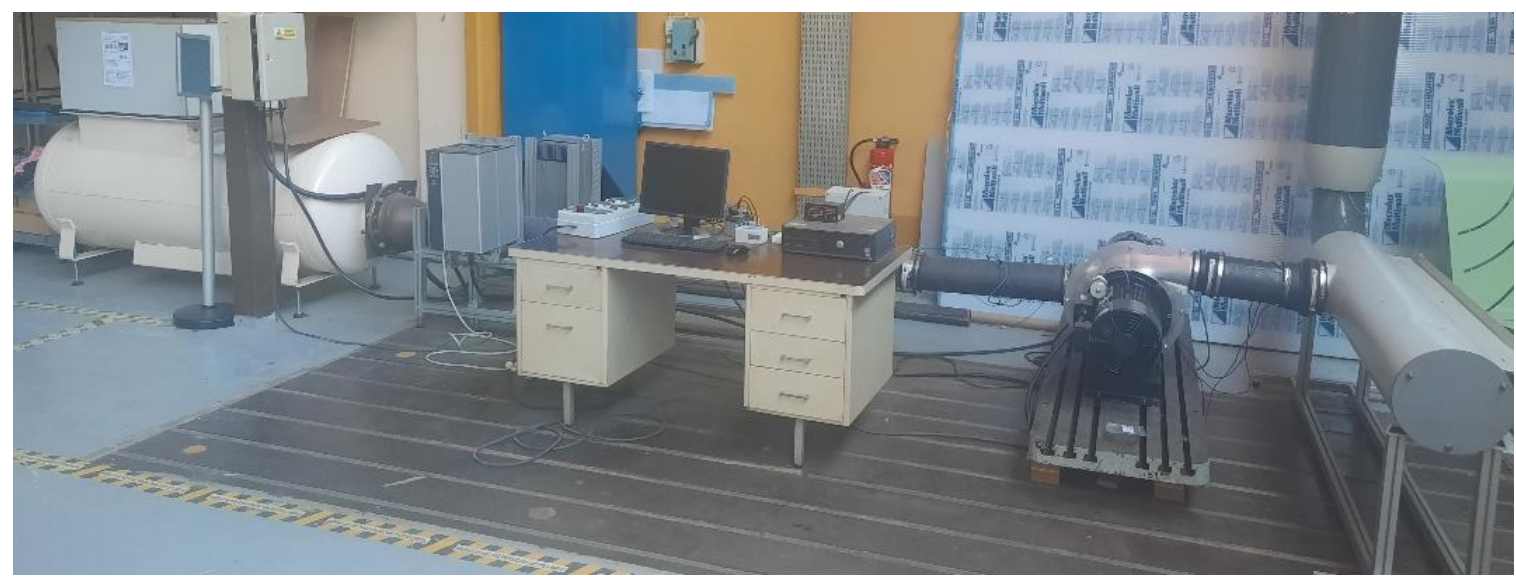

Figure 12. CRCC test rig. 
As the test rig worked on suction application, the outlet pressure of the CRCC was the ambient atmospheric pressure measured at the time of each measurement experience. The test rig was a gas open loop and all of its components were connected through a tubular pipeline of a diameter $D_{\text {pipe }}=158.5 \mathrm{~mm}$, with a tank placed upstream of the CRCC and a muffler at its downstream, connected to the outlet of the volute in order to reduce noise as shown by Figure 13. Also, at the upper of the tank, a manual valve was placed to control the amount of the aspired air into the compressor. To avoid distortion of the aspired air when its direction is changed from vertical to horizontal, and to obtain reliable measurements, a honeycomb was placed upstream of the compressor at the outlet of the tank. FR and RR impellers were driven by two electric motors in which their rotational speeds were controlled by two inverters. The maximum speed (allowing by the motors) of the FR impellers was $16.2 \mathrm{kRPM}$ while that of RR impeller was kept similar to the SR impeller and equal to: $13 \mathrm{kRPM}$.

The measurements were carried out in such a way that at each speed of the RR, the speed of the FR was changed in order to obtain an overall performance map within the limit authorized by the electric motors. The rotational speed of the RR was fixed at those available for the SR impellers, always for the purpose of comparison.

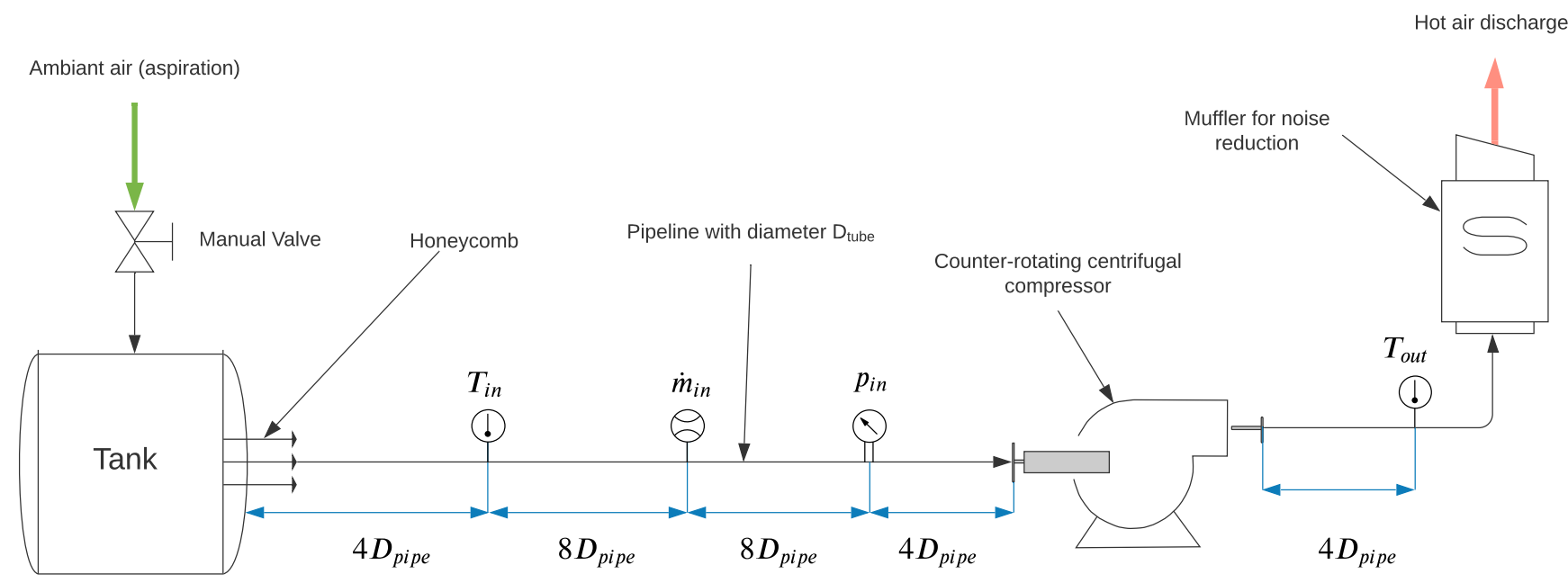

Figure 13. Test rig instrumentation.

\subsection{Measurement Method}

The measurements carried out to obtain the performance curves of the CRCC and SR configurations followed the standard EN ISO 18740-2016 [35]. The position of all sensors are shown in Figure 13 except for two dynamic Kisler static pressure probes, which are shown in Figure 14 in which one was placed at the inlet of the FR impeller, $p_{i, 1}$ while the second one was between the FR and RR impellers, $p_{i, 1,2}$. To identify the surge point graphically during the measurement, an FFT was performed instantaneously during the measurement of the signals of the pressure given by $p_{i, 1}$ and $p_{i, 1,2}$.

Also, a static pressure differential manometer FC332 was connected to the pipeline by a piezoelectric ring with four pressure taps positioned at the circumference to measure the inlet static pressure $p_{\text {in }}$ difference with the ambient atmospheric pressure. This pressure probe was positioned at a distance equal to $4 D_{\text {pipe }}$ upstream of the compressor. As the compressor work in aspiration application, the outlet pressure was equal to the atmospheric ambient air pressure measured by a standard manometer.

For the measurement of the compressor temperature, a sensor $P t_{100}$ was used to measure the inlet temperature $T_{i n}$ and was located at a distance of $20 D_{\text {pipe }}$ upstream of the compressor. To measure the outlet temperature of the system $T_{\text {out }}$, the same three temperature sensors positioned on the circumferential of the pipeline were used and were located at $4 D_{\text {pipe }}$ downstream of the volute of compressor. 
The mass flow rate $\dot{m}_{\text {in }}$ was measured by a Platon Pitot tube connected to an FC66 manometer located at $12 D_{\text {pipe }}$ upstream of the compressor. The global measurement errors $e_{e r}=0.5\left(e_{p}+e_{m}\right)$ made by each sensor were the result of uncertainty on the measurement device, $e_{p}$ and the random error of the measurement depending on the number of evaluation points, $e_{m}$. Those errors were calculated for each parameter following the well known procedure presented in Reference [36]. The inverters at each measured point provide the rotational speed and electric power consumption of the motors that drive both FR and RR impellers. This electrical power consumption is actually the sum of the gas power consumption and the mechanical friction loss power. However, in this study, we are only interested in the aerodynamic performance behavior of SR and CRCC.

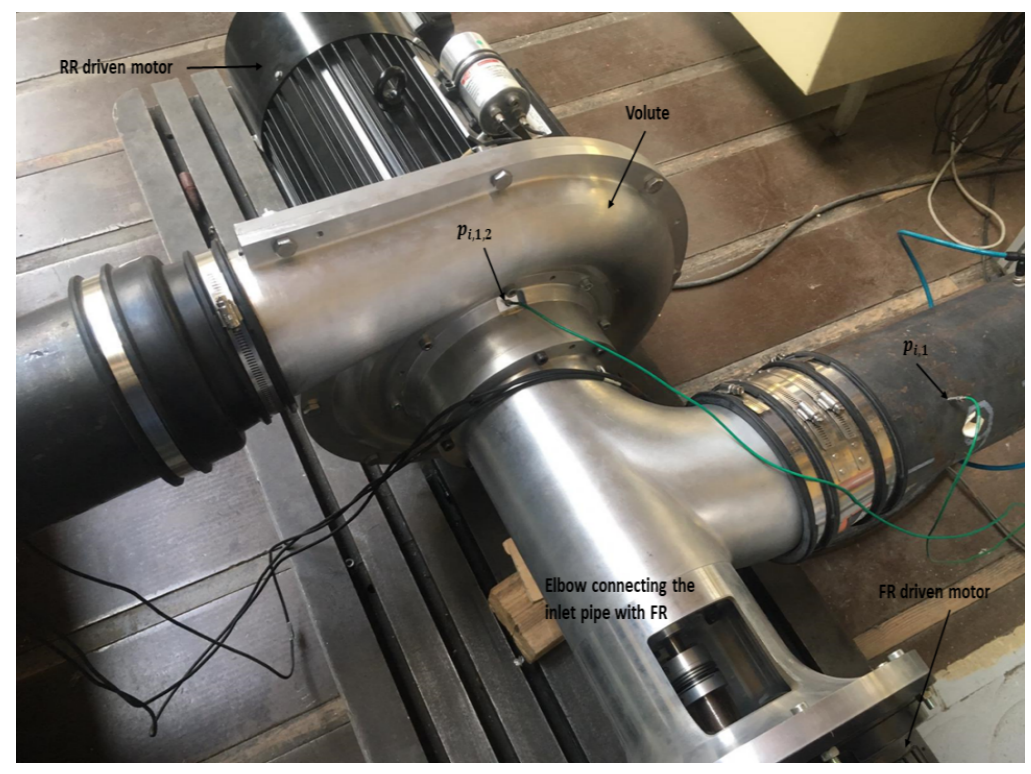

Figure 14. View of the CRCC with the position of two Kisler probes.

\section{Results and Validation}

The global performances are expressed by the static to static pressure rise coefficient and corresponding isentropic efficiency of the whole machine for both CRCC and SR and are given by Equations (1) and (2) respectively.

$$
\begin{gathered}
\psi_{s-s}=\frac{p_{\text {out }}-p_{\text {in }}}{\frac{1}{2} \cdot \rho_{\text {in }} \cdot U^{2}} \\
\eta_{i s, s-s}=\frac{\left(\frac{p_{\text {ou }}}{p_{\text {in }}}\right)^{\frac{\gamma-1}{\gamma}}-1}{\frac{T_{\text {out }}}{T_{\text {in }}}-1} .
\end{gathered}
$$

$U$ is the peripheral speed of SR or RR impeller and $p_{\text {out }}$ is the atmospheric pressure at the time of measurement.

Figures 15 and 16 show a CRCC design validation by experimental and numerical results. Indeed, the CRCC was designed at $\dot{m}_{c}=0.63 \mathrm{~kg} \cdot \mathrm{s}^{-1}$ and with speeds of $N_{F R}=$ $17 \mathrm{kRPM}$ and $N_{F R}=13 \mathrm{kRPM}$. However, the actual drive motor of the FR impeller could only run at a maximum speed of $16.2 \mathrm{kRPM}$ and cannot reach $17 \mathrm{kRPM}$. To validate the design method of CRCC, CFD calculations were performed at a two speed ratio in order to validate the design method of CRCC configuration:

- A first simulation was performed at $N_{F R}=16.2 \mathrm{kRPM}$ and $N_{F R}=13 \mathrm{kRPM}$ to validate the numerical method against the experimental one and are indeed in good agreement as shown in Figures 15 and 16.

- $\quad$ The second simulation was performed at design conditions: $N_{F R}=17 \mathrm{kRPM}$ and $N_{F R}=13 \mathrm{kRPM}$. The numerical results show that the pressure ratio given by CFD 
is also in good agreement with the design point with a small difference. Also, there is a difference of 4 points of isentropic efficiency between the target design with an adapted volute (point $A_{1}$ ) and the one with the SR volute (point $A_{2}$ ).

The performances of some points of interest $\left(A_{1}\right.$ à $\left.A_{6}\right)$ presented in Figures 15 and 16 are shown in Table 3.

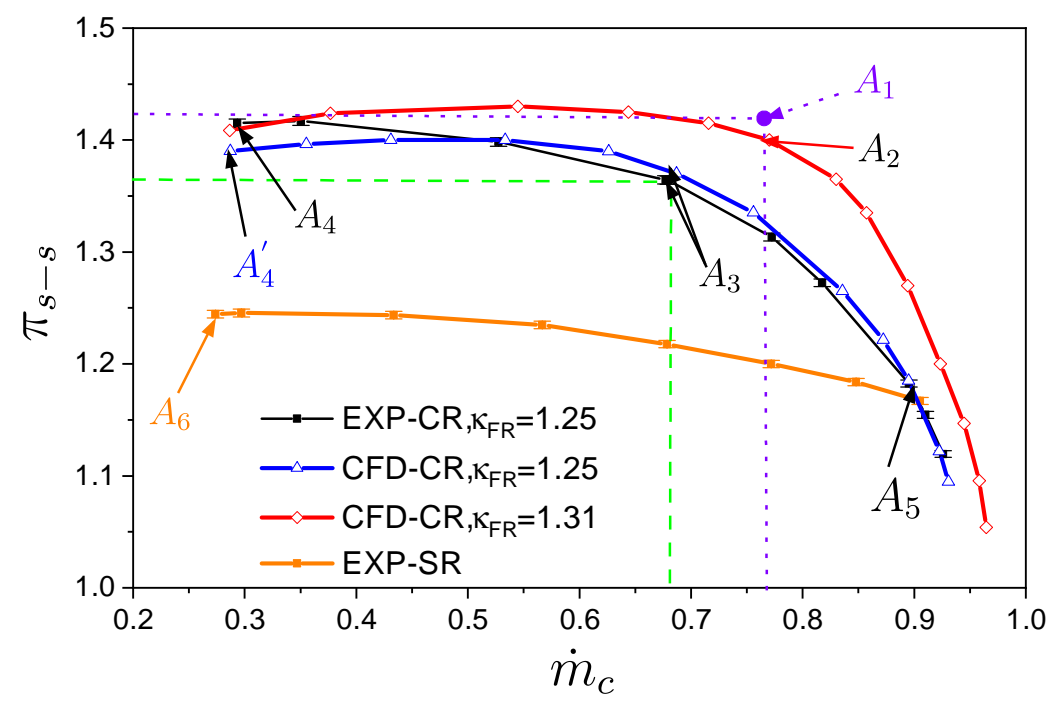

Figure 15. Comparison between the static to static pressure ratio obtained from experimental results and CFD of CRCC at various speed ratio $\kappa_{F R}$ and that given by SR: $N_{R R}=N_{S R}=13 \mathrm{kRPM}$.

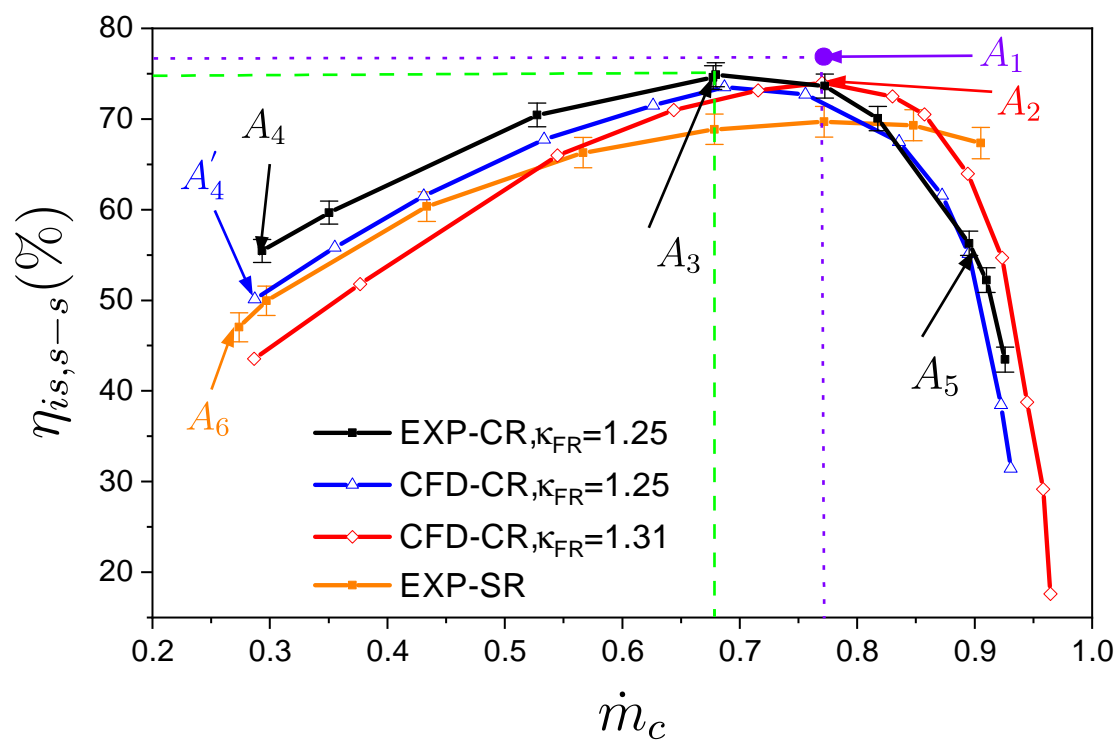

Figure 16. Comparison between the static to static isentropic efficiency obtained from experimental results and CFD of CRCC at various speed ratio $\kappa_{F R}$ and that given by SR: $N_{R R}=N_{S R}=13 \mathrm{kRPM}$. 
Table 3. Experimental aerodynamic characteristic of some points $A_{1}$ à $A_{6}$ presented in Figures 15 and 16.

\begin{tabular}{ccccccc}
\hline Point & $\dot{m}_{\boldsymbol{c}}$ & $\dot{\boldsymbol{m}}$ & $\pi_{\boldsymbol{s}-\mathrm{s}, \text { EXP }}$ & $\pi_{s-s, C F D}$ & $\eta_{i s, s-s, E X P}$ & $\eta_{i s, s-s, C F D}$ \\
\hline$A_{1}$ & $0.77 \mathrm{~kg} \cdot \mathrm{s}^{-1}$ & $0.55 \mathrm{~kg} \cdot \mathrm{s}^{-1}$ & - & 1.42 & - & $77.05 \%$ \\
$A_{2}$ & $0.77 \mathrm{~kg} \cdot \mathrm{s}^{-1}$ & $0.55 \mathrm{~kg} \cdot \mathrm{s}^{-1}$ & - & 1.405 & - & $74.01 \%$ \\
$A_{3}$ & $0.67 \mathrm{~kg} \cdot \mathrm{s}^{-1}$ & $0.51 \mathrm{~kg} \cdot \mathrm{s}^{-1}$ & $1.36 \pm 3.62 \times 10^{-3}$ & 1.37 & $74.81 \pm 1.31 \%$ & $73.53 \%$ \\
$A_{4}$ & $0.29 \mathrm{~kg} \cdot \mathrm{s}^{-1}$ & $0.20 \mathrm{~kg} \cdot \mathrm{s}^{-1}$ & $1.41 \pm 3.95 \times 10^{-3}$ & - & $55.45 \pm 1.27 \%$ & - \\
$A_{4}^{\prime}$ & $0.28 \mathrm{~kg} \cdot \mathrm{s}^{-1}$ & $0.20 \mathrm{~kg} \cdot \mathrm{s}^{-1}$ & - & 1.39 & - & $48.15 \%$ \\
$A_{5}$ & $0.89 \mathrm{~kg} \cdot \mathrm{s}^{-1}$ & $0.75 \mathrm{~kg} \cdot \mathrm{s}^{-1}$ & $1.18 \pm 3.14 \times 10^{-3}$ & 1.19 & $56.29 \pm 1.35 \%$ & $55.14 \%$ \\
$A_{6}$ & $0.27 \mathrm{~kg} \cdot \mathrm{s}^{-1}$ & $0.21 \mathrm{~kg} \cdot \mathrm{s}^{-1}$ & $1.24 \pm 3.46 \times 10^{-3}$ & - & $47.02 \pm 1.6 \%$ & - \\
\hline
\end{tabular}

The details of the numerical procedure are not shown in this study as its main focus is on experimental performances. However, Figure 17 shows the streamline of CRCC on a surface between hub and shroud at the design point $\left(A_{2}\right)$. This figure shows that the flow follows the blades of the FR and the RR perfectly. At the leading edge of the RR, the relative velocity of the flows is increased dramatically thanks to the CR effect.

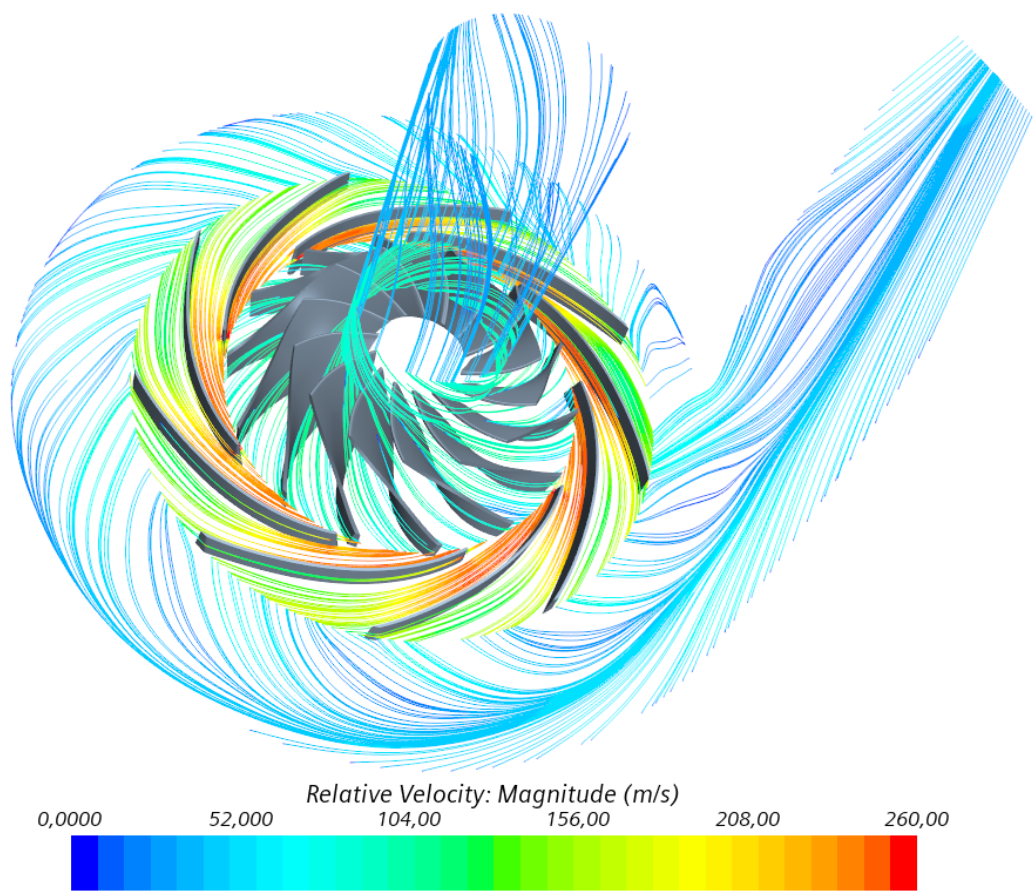

Figure 17. Streamlines visualisation in CRCC at the design conditions $\left(A_{2}\right)$.

One can see in Figures 18 and 19 that, at the design point, there is an increase by two of the pressure rise coefficient given by CRCC and also an increase of the isentropic efficiency by almost 5 points compared to SR.

When it comes to the speed ratio of CRCC: $\kappa_{F R}=N_{F R} / N_{R R}$, increasing $\kappa_{F R}$ at fixed $N_{R R}$ increase the chock margin and shifting the best efficiency point toward higher mass flow rate. The same opposite observation can be made, when decreasing $\kappa_{F R}$ the higher efficiency point is shifted toward a low mass flow rate with a small increase of surge margin. The pressure rise coefficient increases with the increases of $\kappa_{F R}$ and decreases when it decreases. The performance of some points of interest $\left(B_{1}\right.$ à $\left.B_{5}\right)$ presented in Figures 18 and 19 are also shown in Table 4. 


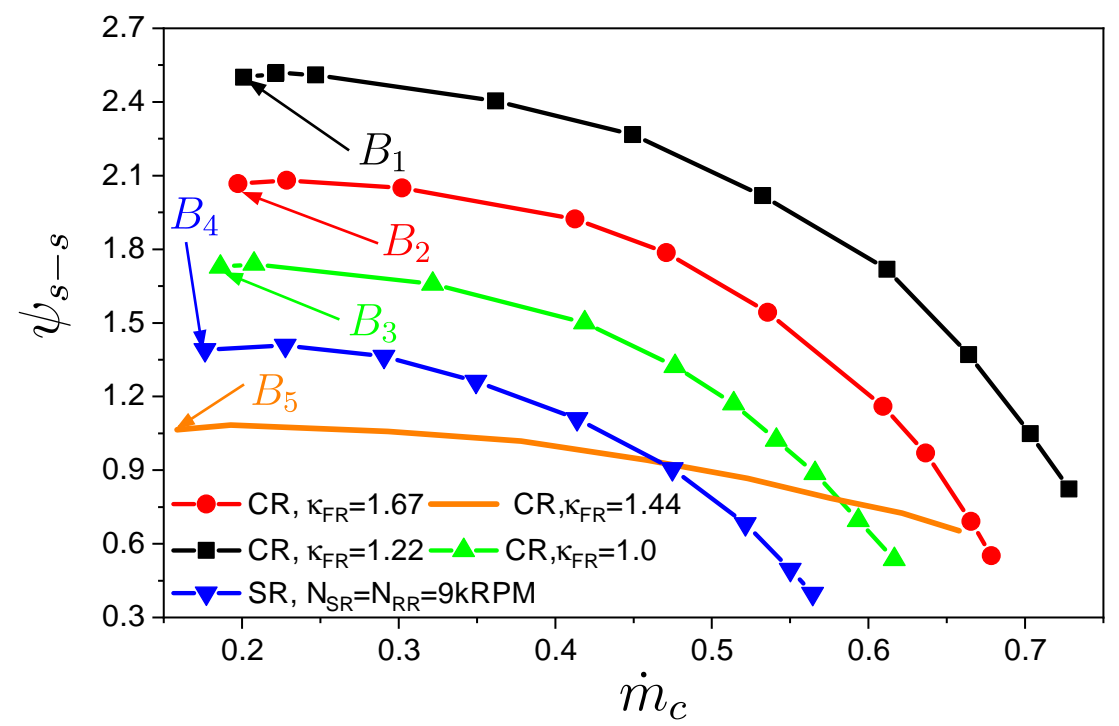

Figure 18. Comparison between the pressure rise coefficient obtained from experimental results of CRCC at various speed ratio $\kappa_{F R}$ and that given by SR: $N_{R R}=N_{S R}=9 \mathrm{kRPM}$.

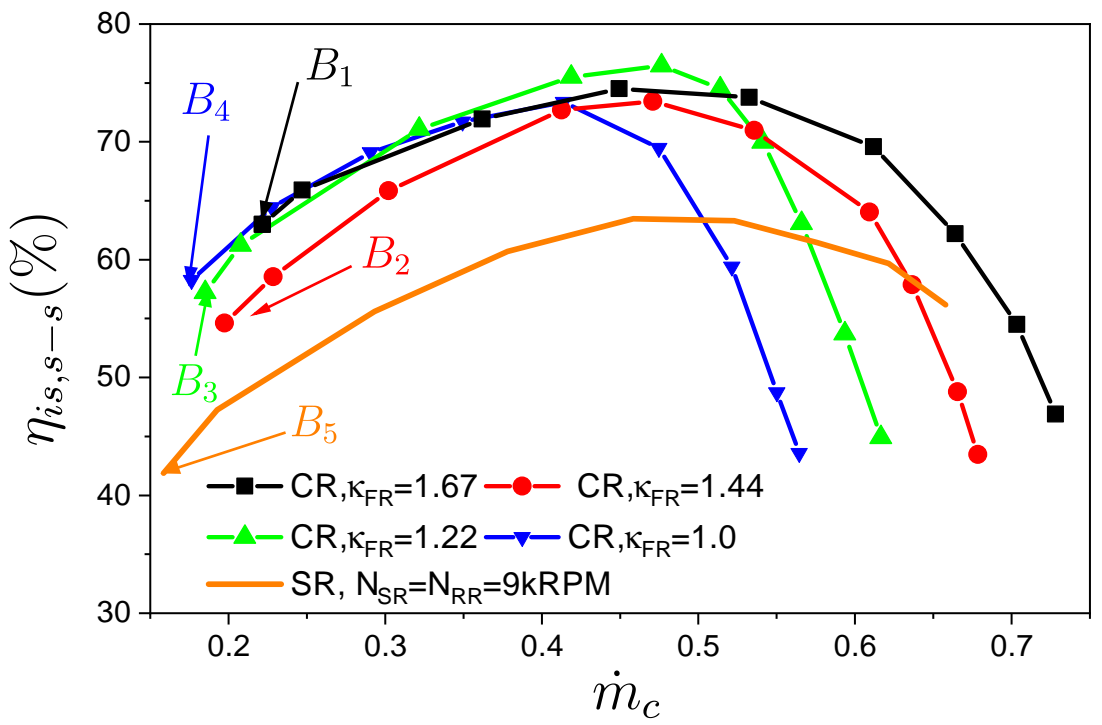

Figure 19. Comparison between the isentropic efficiency obtained from experimental results of CRCC at various speed ratio $\kappa_{F R}$ and that given by SR: $N_{R R}=N_{S R}=9 \mathrm{kRPM}$.

Table 4. Experimental aerodynamic characteristic of some points $B_{1}$ à $B_{5}$ presented in Figures 18 and 19.

\begin{tabular}{ccccc}
\hline Point & $\dot{\boldsymbol{m}}_{\boldsymbol{c}}$ & $\dot{\boldsymbol{m}}$ & $\psi_{\boldsymbol{s}-\boldsymbol{s}, \boldsymbol{E X P}}$ & $\eta_{\boldsymbol{s}-\boldsymbol{s}, \boldsymbol{E X P}}$ \\
\hline$B_{1}$ & $0.22 \mathrm{~kg} \cdot \mathrm{s}^{-1}$ & $0.18 \mathrm{~kg} \cdot \mathrm{s}^{-1}$ & $2.52 \pm 2.57 \times 10^{-2}$ & $62.99 \pm 0.67 \%$ \\
$B_{2}$ & $0.20 \mathrm{~kg} \cdot \mathrm{s}^{-1}$ & $0.16 \mathrm{~kg} \cdot \mathrm{s}^{-1}$ & $2.06 \pm 2.56 \times 10^{-2}$ & $54.63 \pm 0.77 \%$ \\
$B_{3}$ & $0.18 \mathrm{~kg} \cdot \mathrm{s}^{-1}$ & $0.16 \mathrm{~kg} \cdot \mathrm{s}^{-1}$ & $1.73 \pm 1.54 \times 10^{-2}$ & $57.22 \pm 0.56 \%$ \\
$B_{4}$ & $0.17 \mathrm{~kg} \cdot \mathrm{s}^{-1}$ & $0.15 \mathrm{~kg} \cdot \mathrm{s}^{-1}$ & $1.39 \pm 1.94 \times 10^{-2}$ & $58.27 \pm 0.95 \%$ \\
$B_{5}$ & $0.16 \mathrm{~kg} \cdot \mathrm{s}^{-1}$ & $0.14 \mathrm{~kg} \cdot \mathrm{s}^{-1}$ & $1.06 \pm 2.00 \times 10^{-2}$ & $41.89 \pm 1.61 \%$ \\
\hline
\end{tabular}

The same observations are also shown by Figures 20-23 and Tables 5 and 6 . 


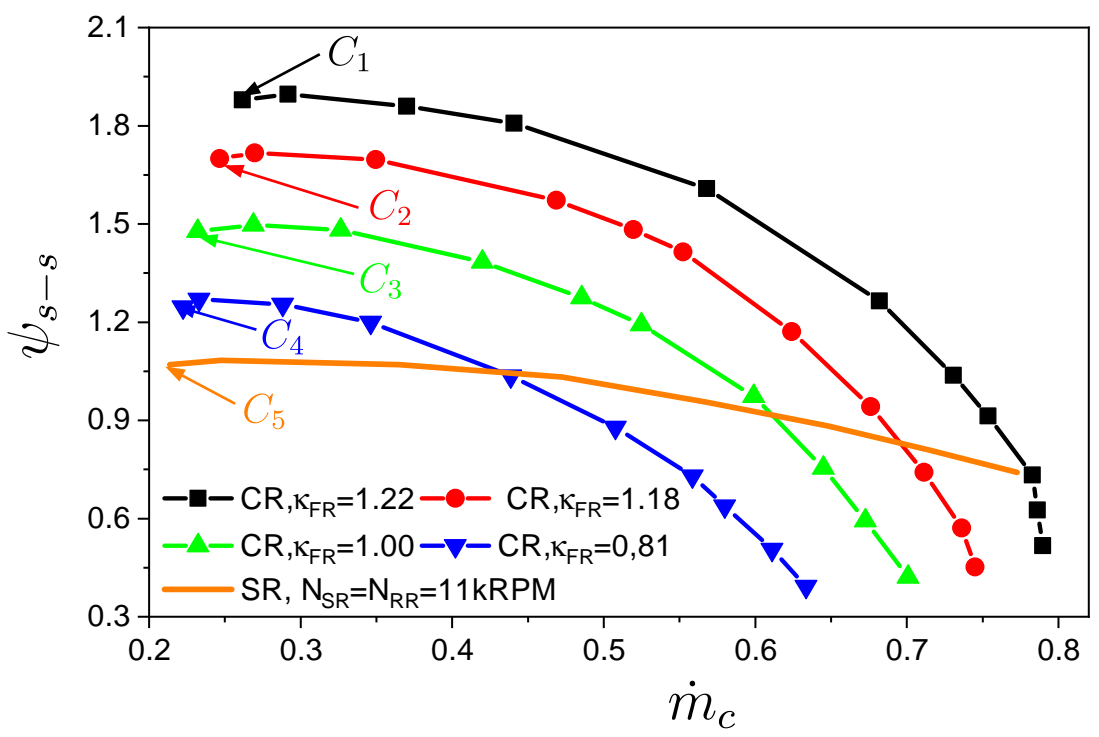

Figure 20. Comparison between the pressure rise coefficient obtained from experimental results of CRCC at various speed ratio $\kappa_{F R}$ and that given by SR: $N_{R R}=N_{S R}=11 \mathrm{kRPM}$.

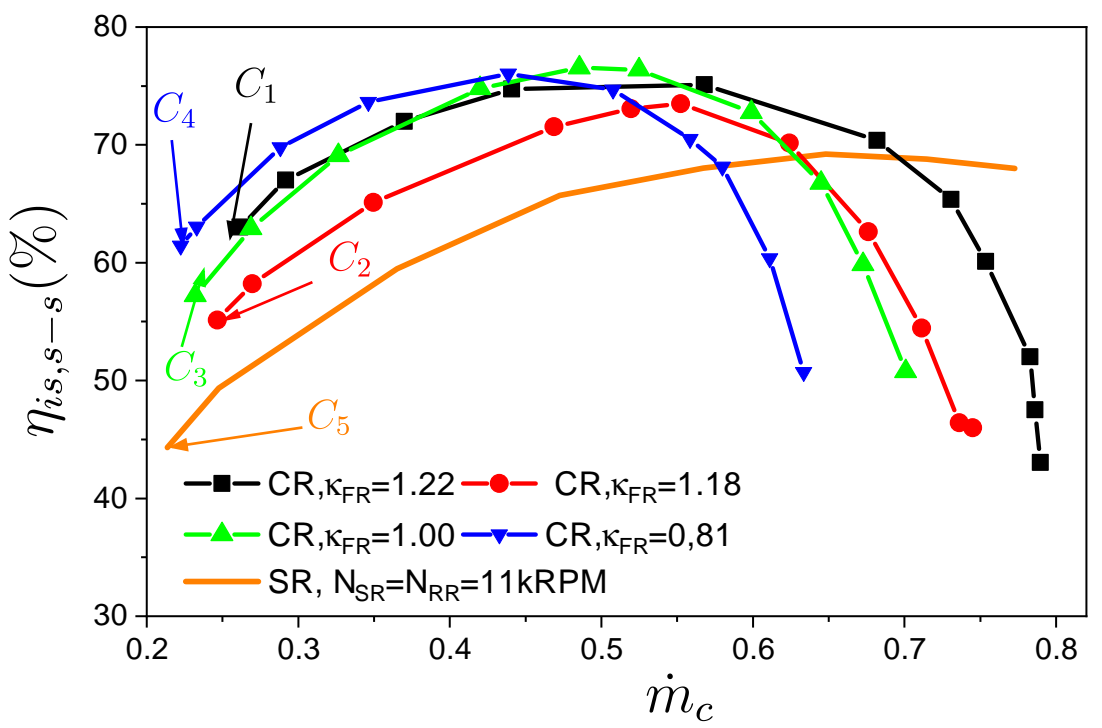

Figure 21. Comparison between the isentropic efficiency obtained from experimental results of CRCC at various speed ratio $\kappa_{F R}$ and that given by SR: $N_{R R}=N_{S R}=11 \mathrm{kRPM}$.

Table 5. Experimental aerodynamic characteristic of some points $C_{1}$ à $C_{5}$ presented in Figures 20 and 21.

\begin{tabular}{ccccc}
\hline Point & $\dot{\boldsymbol{m}}_{\boldsymbol{c}}$ & $\dot{\boldsymbol{m}}$ & $\boldsymbol{\psi}_{\boldsymbol{s}-\boldsymbol{s}, \boldsymbol{E X P}}$ & $\boldsymbol{\eta}_{\boldsymbol{s}-\mathrm{s}, \boldsymbol{E X X}}$ \\
\hline$C_{1}$ & $0.26 \mathrm{~kg} \cdot \mathrm{s}^{-1}$ & $0.2 \mathrm{~kg} \cdot \mathrm{s}^{-1}$ & $1.88 \pm 2.46 \times 10^{-2}$ & $63.03 \pm 0.77 \%$ \\
$C_{2}$ & $0.24 \mathrm{~kg} \cdot \mathrm{s}^{-1}$ & $0.19 \mathrm{~kg} \cdot \mathrm{s}^{-1}$ & $1.70 \pm 1.55 \times 10^{-2}$ & $55.13 \pm 0.75 \%$ \\
$C_{3}$ & $0.23 \mathrm{~kg} \cdot \mathrm{s}^{-1}$ & $0.18 \mathrm{~kg} \cdot \mathrm{s}^{-1}$ & $1.47 \pm 2.01 \times 10^{-2}$ & $57.21 \pm 0.91 \%$ \\
$C_{4}$ & $0.22 \mathrm{~kg} \cdot \mathrm{s}^{-1}$ & $0.18 \mathrm{~kg} \cdot \mathrm{s}^{-1}$ & $1.25 \pm 1.54 \times 10^{-2}$ & $61.45 \pm 0.82 \%$ \\
$C_{5}$ & $0.21 \mathrm{~kg} \cdot \mathrm{s}^{-1}$ & $0.18 \mathrm{~kg} \cdot \mathrm{s}^{-1}$ & $1.07 \pm 1.57 \times 10^{-2}$ & $44.31 \pm 1.52 \%$ \\
\hline
\end{tabular}




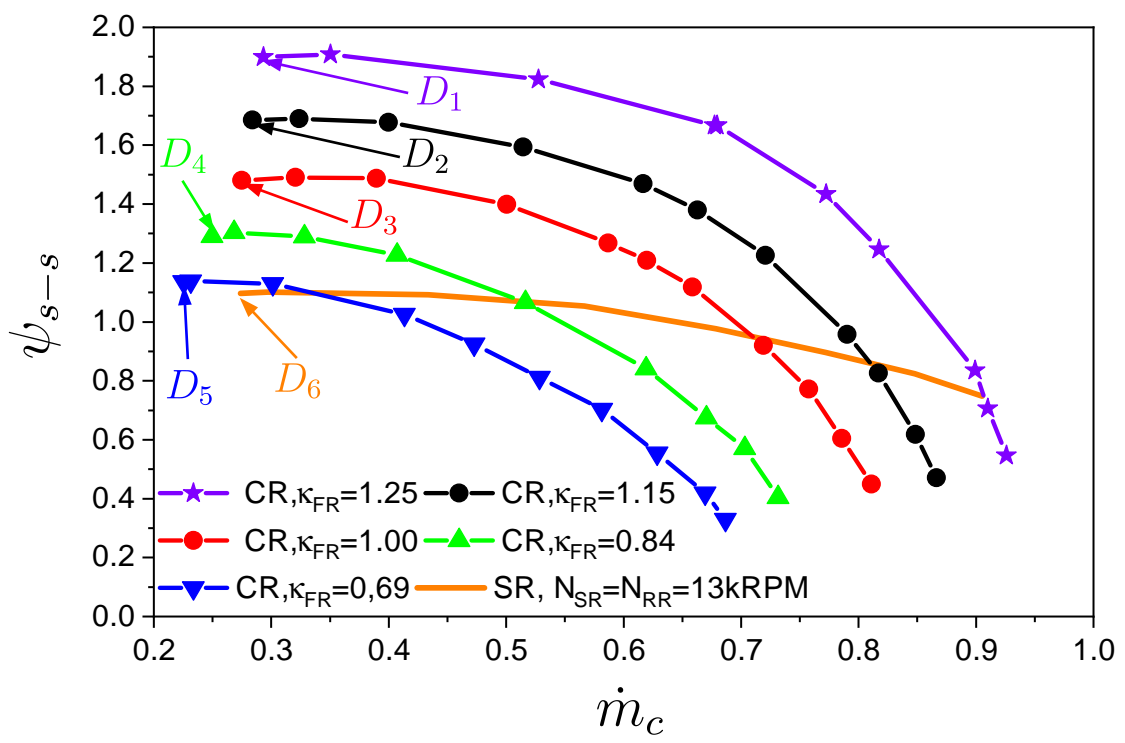

Figure 22. Comparison between the pressure rise coefficient obtained from experimental results of CRCC at various speed ratio $\kappa_{F R}$ and that given by SR: $N_{R R}=N_{S R}=13 \mathrm{kRPM}$.

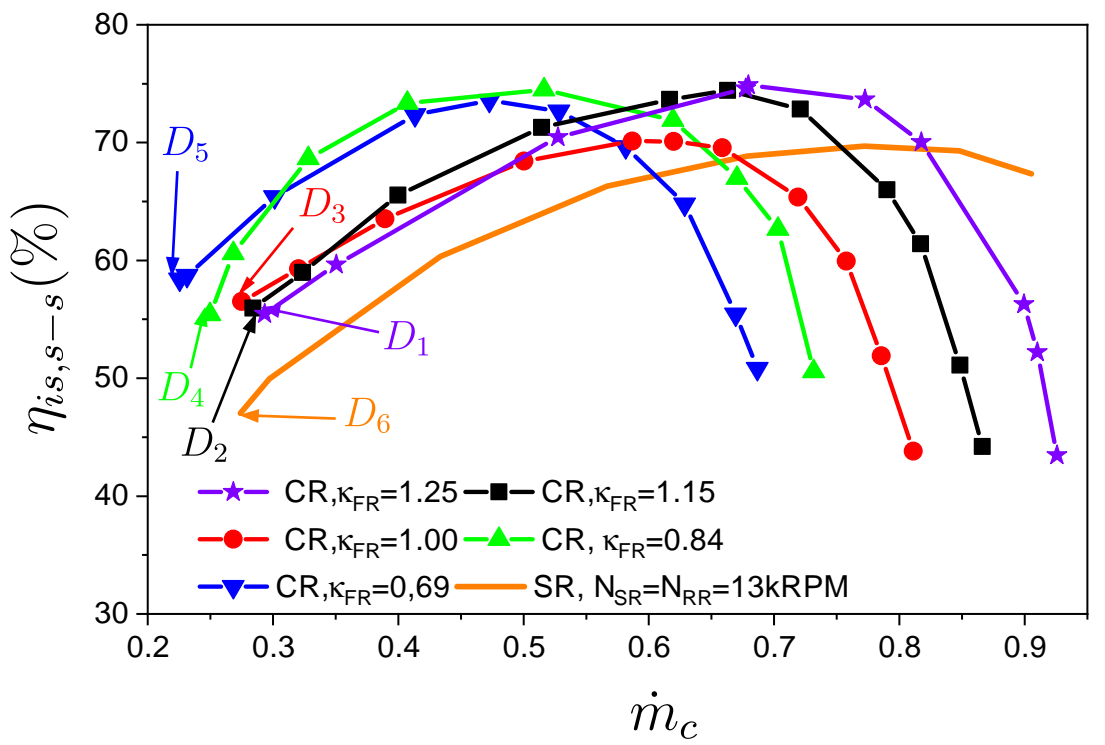

Figure 23. Comparison between the isentropic efficiency obtained from experimental results of CRCC at various speed ratio $\kappa_{F R}$ and that given by SR: $N_{R R}=N_{S R}=13 \mathrm{kRPM}$.

Table 6. Experimental aerodynamic characteristic of some points $D_{1}$ à $D_{5}$ presented in Figures 22 and 23.

\begin{tabular}{ccccc}
\hline Point & $\dot{m}_{\boldsymbol{c}}$ & $\dot{m}$ & $\psi_{s-s, \text { EXP }}$ & $\eta_{s-s, \text { EXP }}$ \\
\hline$D_{1}$ & $0.26 \mathrm{~kg} \cdot \mathrm{s}^{-1}$ & $0.2 \mathrm{~kg} \cdot \mathrm{s}^{-1}$ & $1.88 \pm 1.5 \times 10^{-2}$ & $63.03 \pm 1.27 \%$ \\
$D_{2}$ & $0.24 \mathrm{~kg} \cdot \mathrm{s}^{-1}$ & $0.19 \mathrm{~kg} \cdot \mathrm{s}^{-1}$ & $1.70 \pm 2.06 \times 10^{-2}$ & $55.13 \pm 0.74 \%$ \\
$D_{3}$ & $0.23 \mathrm{~kg} \cdot \mathrm{s}^{-1}$ & $0.18 \mathrm{~kg} \cdot \mathrm{s}^{-1}$ & $1.47 \pm 2.06 \times 10^{-2}$ & $57.21 \pm 0.84 \%$ \\
$D_{4}$ & $0.22 \mathrm{~kg} \cdot \mathrm{s}^{-1}$ & $0.18 \mathrm{~kg} \cdot \mathrm{s}^{-1}$ & $1.25 \pm 1.55 \times 10^{-2}$ & $61.45 \pm 0.63 \%$ \\
$D_{5}$ & $0.21 \mathrm{~kg} \cdot \mathrm{s}^{-1}$ & $0.18 \mathrm{~kg} \cdot \mathrm{s}^{-1}$ & $1.07 \pm 2.22 \times 10^{-2}$ & $44.31 \pm 0.70 \%$ \\
$D_{6}$ & $0.29 \mathrm{~kg} \cdot \mathrm{s}^{-1}$ & $0.23 \mathrm{~kg} \cdot \mathrm{s}^{-1}$ & $1.10 \pm 2.01 \times 10^{-2}$ & $44.31 \pm 1.6 \%$ \\
\hline
\end{tabular}

In order to compare the overall performances of the CRCC with those of the SR presented in Figure 1, Figures 24-26 show the performance maps of CRCC for each speed of RR. Indeed, for each performance curve at a fixed speed of SR presented in the Figure 1, 
CRCC can provide an entire performance map with different speeds of FR by keeping the speed of RR equal to that of SR, fixed for each map.

These figures show that the efficiency is much better concentrated at a low mass flow rate compared to SR. They also show that this area of maximum efficiency can be shifted toward high and low mass flow rates, according to the modulation of speed ratio.

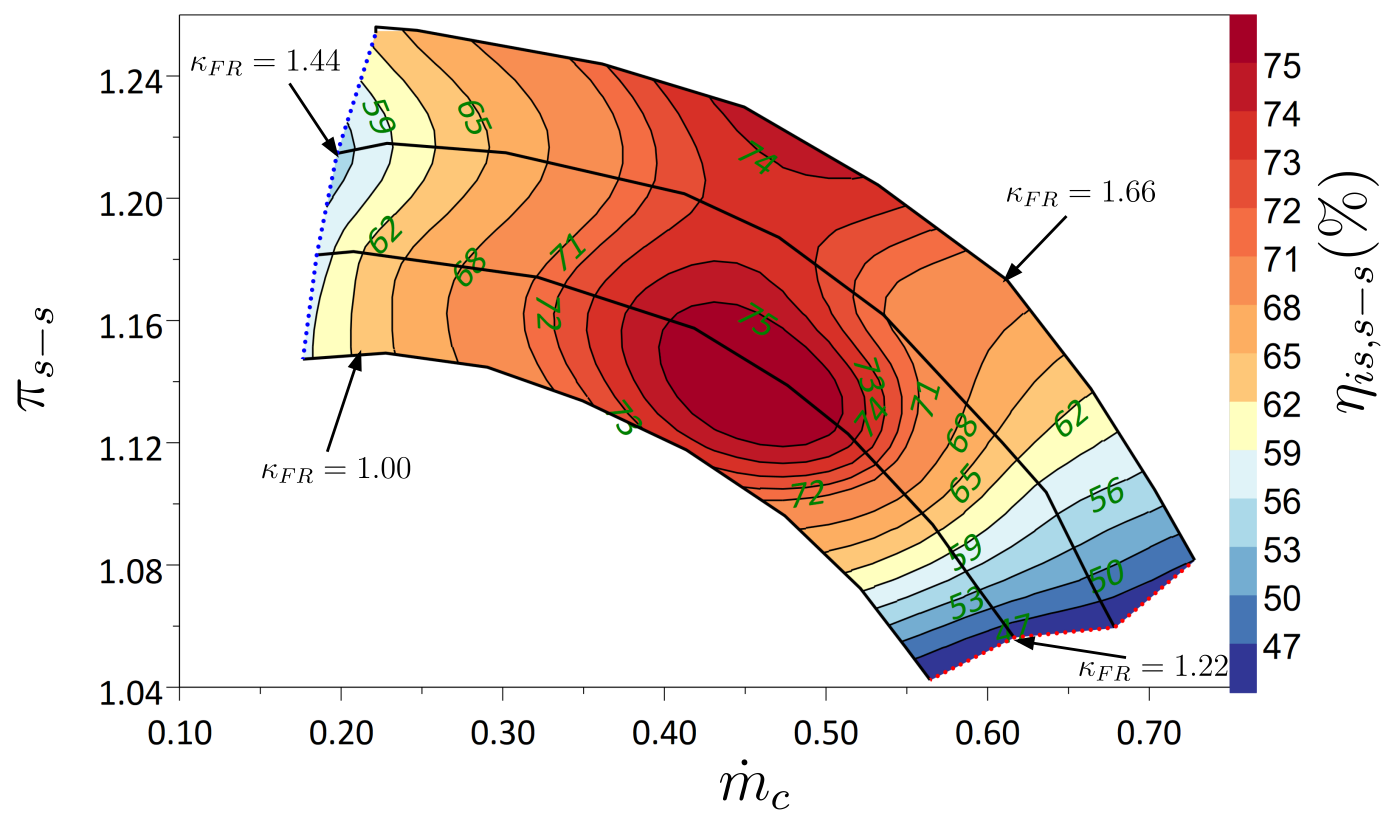

Figure 24. Experimental conventionnal performance map of CRCC at various speed ratio $\kappa_{F R}$ with: $N_{R R}=9 \mathrm{kRPM}$.

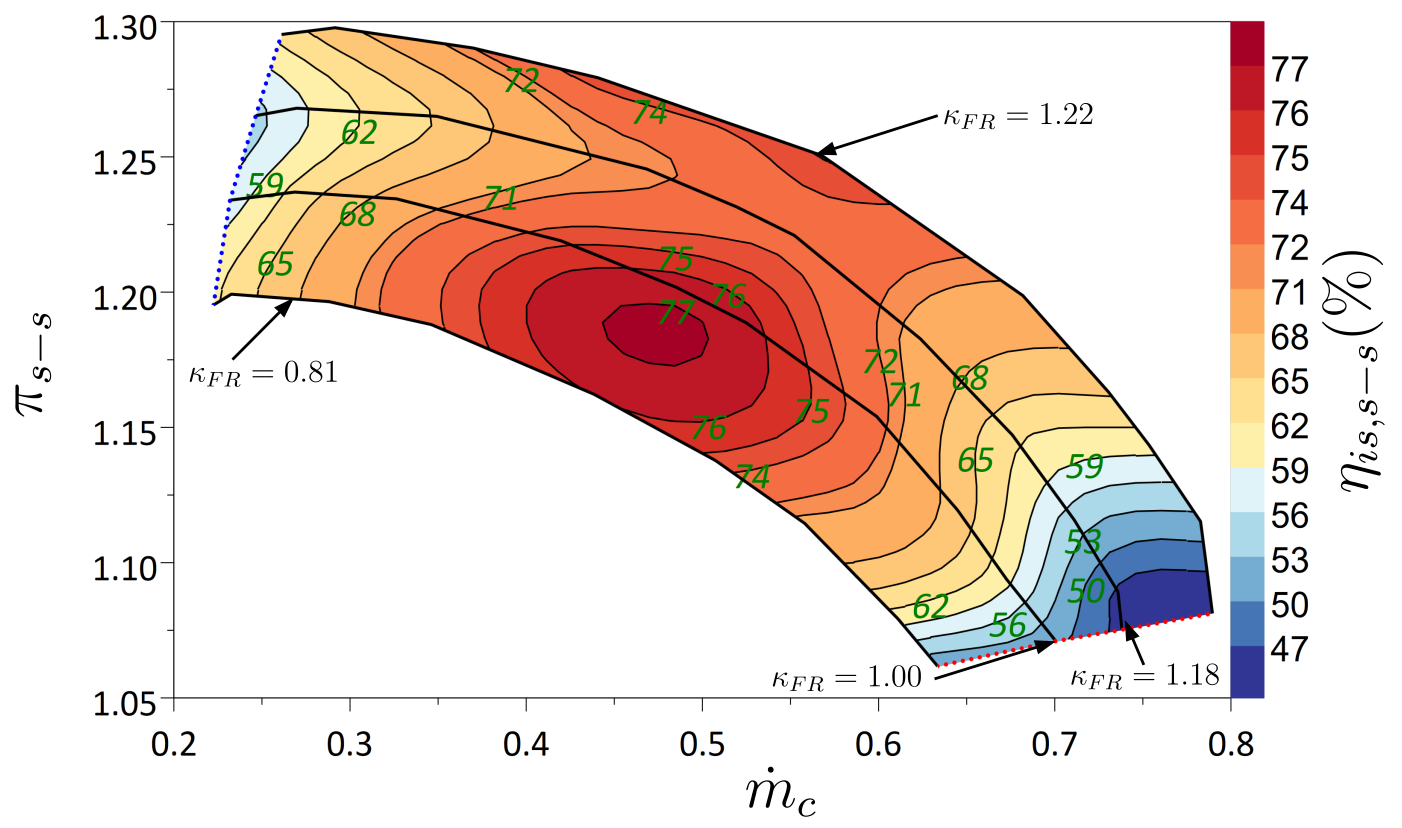

Figure 25. Experimental conventionnal performance map of CRCC at various speed ratio $\kappa_{F R}$ with: $N_{R R}=11 \mathrm{kRPM}$. 


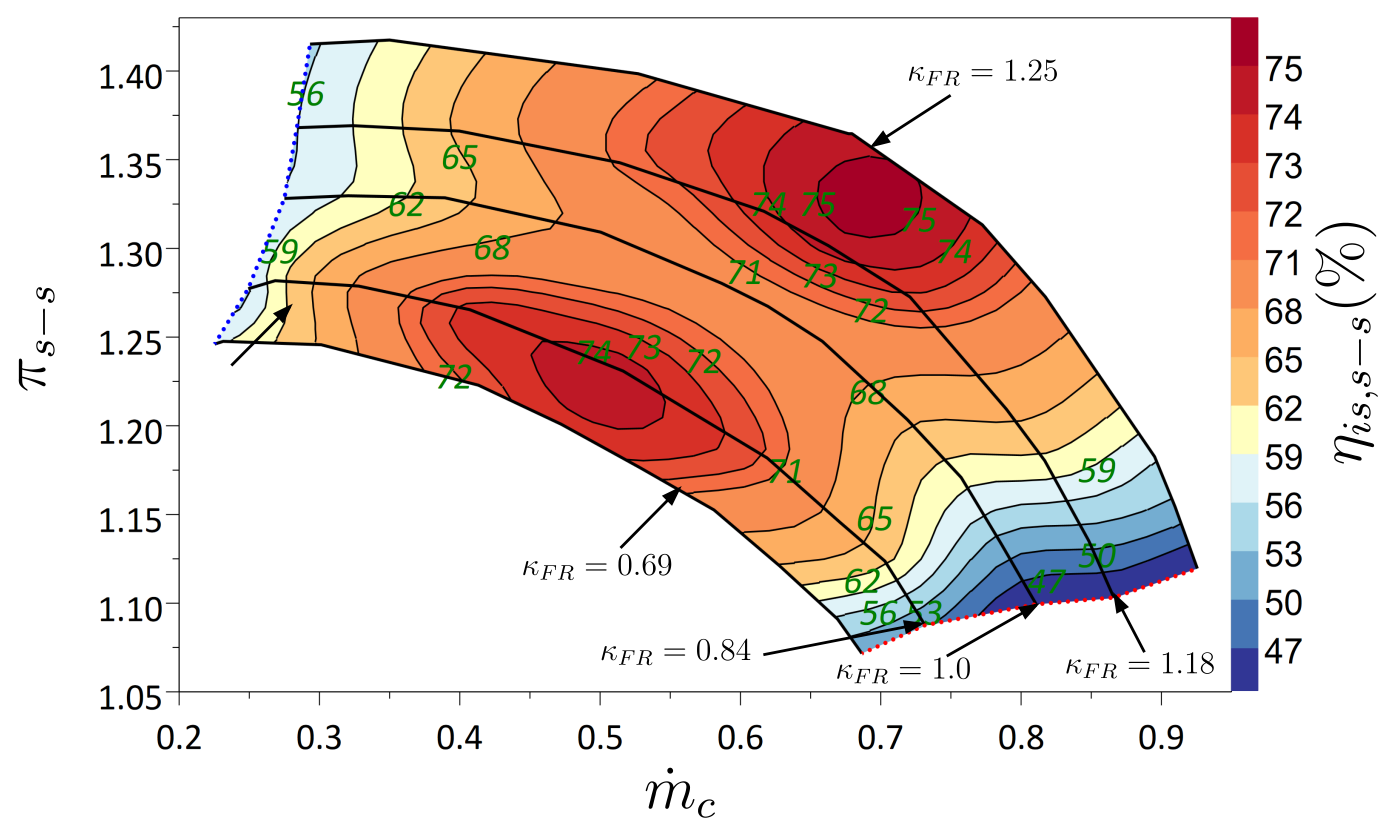

Figure 26. Experimental conventionnal performance map of CRCC at various speed ratio $\kappa_{F R}$ with: $N_{R R}=13 \mathrm{kRPM}$.

\section{Conclusions}

First, the objective of this work was to present a first experimental validation of a design method adapted to an innovative CRCC using two successive impellers.

Then, the aim of the study was also to investigate experimentally the aerodynamic performances of this new layout compared to a baseline. Indeed, the results show that this innovative configuration can increase the pressure rise by a factor of two at design conditions and produce a high-pressure rise coefficient on the overall global performance map compared to the baseline. An increase of efficiency is also observed on the overall map.

The results also show that the speed ratio has a positive effect on the performance and allows a shift of the maximum efficiency and pressure rise coefficient toward high and low mass flow rates, depending on the user's wish.

Moreover, the main weakness of this new layout is the chock margin; even if this latter can be increased by the speed ratio, its remains the major handicap of this new turbomachine, which the designer should pay attention to.

Author Contributions: Conceptualization, C.B.A., S.K. and F.B.; methodology, C.B.A., S.K. and F.B.; software, C.B.A., M.D., M.S. and S.K.; validation, C.B.A.; formal analysis, C.B.A.; investigation, C.B.A.; resources, S.K., M.D. and F.B.; data curation, C.B.A. and S.K.; writing-original draft preparation, C.B.A., M.D. and S.K.; writing-review and editing, C.B.A., M.D., S.K. and F.B.; visualization, C.B.A. and M.S.; supervision, M.D., S.K., A.E.M. and F.B.; project administration, S.K. and M.D.; funding acquisition, S.K. and F.B. All authors have read and agreed to the published version of the manuscript.

Funding: This research received no external funding.

Institutional Review Board Statement: Not applicable.

Informed Consent Statement: Not applicable.

Data Availability Statement: The data presented in this study are available on request from thecorresponding author.

Conflicts of Interest: The authors declare no conflict of interest. 


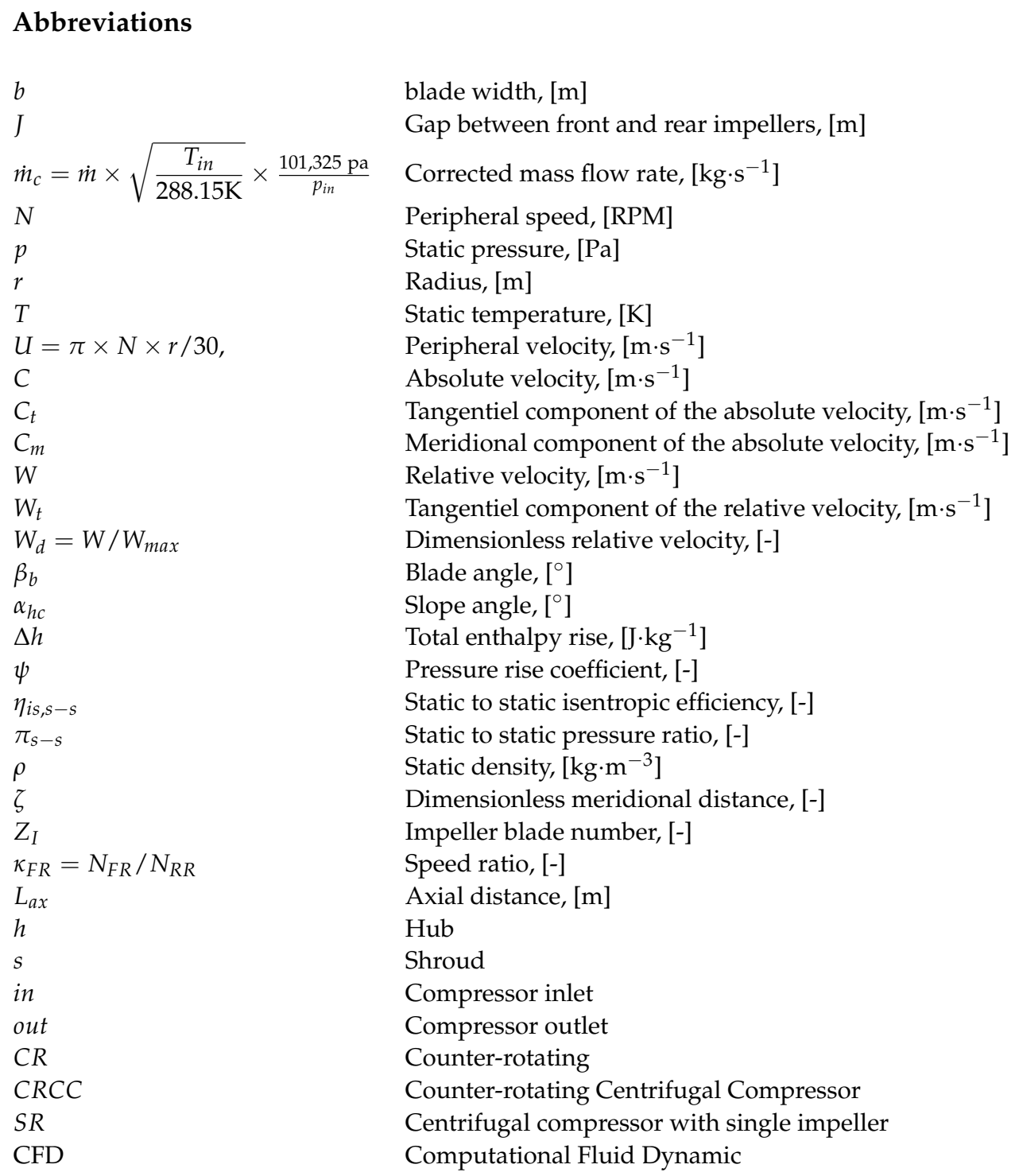

\section{References}

1. Bourne, J. A Treatise on the Screw Propeller: With Various Suggestions of Improvement; Franklin Classics: Franklin, TN, USA, 1855.

2. Lesley, E.P. Experiments with a Counter-Propeller; American Institute of Aeronautics and Astronautics: Reston, VA, USA, 1933.

3. Sharma, P.; Jain, Y.; Jha, N.; Khanna, B. Stalling behaviour of a contra-rotating axial compressor stage. In Proceedings of the 7th International Symposium on Air Breathing Engines, Beijing, China, 2-6 September 1985; pp. 734-740.

4. Sharma, P.; Jain, Y.; Pundhir, D. A study of some factors affecting the performance of a contra-rotating axial compressor stage. Proc. Inst. Mech. Eng. Part A Power Process. Eng. 1988, 202, 15-21. [CrossRef]

5. Sharma, P.; Pundhir, D. A study of flow structure in a contra-rotating axial compressor stage. In Proceedings of the 9th International Symposium on Air Breathing Engines, Athens, Greece, 3-8 September 1989; pp. 237-244.

6. Pundhir, D.; Sharma, P. A Study of aerodynamic performance of a contra rotating axial compressor stage. Def. Sci. J. 1992, 42, 191-199. [CrossRef]

7. Gao, L.; Li, R.; Miao, F.; Cai, Y. Unsteady Investigation on Tip Flow Field and Rotating Stall in Counter-Rotating Axial Compressor. J. Eng. Gas Turbines Power 2015, 137, 072603. [CrossRef]

8. Dejour, Q.; Vo, H.D. Assessment of a Novel Non-Axial Counter-Rotating Compressor Concept for Aero-Engines. In Proceedings of the ASME Turbo Expo 2018: Turbomachinery Technical Conference and Exposition, Lillestrøm, Norway, 11-15 June 2018.

9. Nouri, H.; Ravelet, F.; Bakir, F.; Sarraf, C.; Rey, R. Design and Experimental Validation of a Ducted Counter-Rotating Axial-Flow Fans System. J. Fluids Eng. 2012, 134, 104504. [CrossRef]

10. Nouri, H.; Danlos, A.; Ravelet, F.; Bakir, F.; Sarraf, C. Experimental Study of the Instationary Flow Between Two Ducted Counter-Rotating Rotors. J. Eng. Gas Turbines Power 2013, 135, 022601. [CrossRef]

11. Wang, J.; Ravelet, F.; Bakir, F. Performance gains provided by the use of a counter-rotating axial-flow fan with respect to a conventional rotor-stator stage. J. Energy Power Sources 2015, 2, 9. 
12. Ravelet, F.; Bakir, F.; Sarraf, C.; Wang, J. Experimental investigation on the effect of load distribution on the performances of a counter-rotating axial-flow fan. Exp. Therm. Fluid Sci. 2018, 96, 101-110. [CrossRef]

13. Cao, L.; Honda, H.; Yoshimura, H.; Watanabe, S.; Furukawa, A. Experimental Investigation of Blade Rows Interactions in Contra-Rotating Axial Flow Pump. Available online: https://asmedigitalcollection.asme.org/FEDSM/proceedings-abstract/ FEDSM2014/46223/V01BT10A040/233119 (accessed on 10 January 2021).

14. Cao, L.; Watanabe, S.; Furukawa, A.; Wu, D. Numerical Investigation of Influence of Rotor-Rotor Gap on Performances of Contra-Rotating Axial Flow Pump. Available online: https:/ / asmedigitalcollection.asme.org/FEDSM/proceedings-abstract/ AJKFluids2015/57212/V001T33A002/227935 (accessed on 10 January 2021).

15. Honda, H.; Cao, L.; Watanabe, S.; Tsuda, S.-i.; Furukawa, A. Numerical Investigation on Performance of Contra-Rotating Axial Flow Pump with Different Rear Rotor Design. Available online: https://asmedigitalcollection.asme.org/FEDSM/proceedingsabstract/ AJKFluids2015/V01AT33A011/274537 (accessed on 10 January 2021).

16. Fukutomi, J.; Shigemitsu, T.; Yasunobu, T. Performance and internal flow of sirocco fan using contra-rotating rotors. J. Therm. Sci. 2008, 17, 35. [CrossRef]

17. Tosin, S.; Friedrichs, J.; Dreiss, A. Pumping Unit Power-Density Improvement by Application of Counter-Rotating Impellers Design. J. Turbomach. 2016, 138. [CrossRef]

18. Price, N.C. Counterrotating Supercharger. U.S. Patent 384539A, 21 March 1941.

19. Christian Friebe, K.H. Centrifugal Compressor with Counter-Rotating Compressor Impellers. D.E. Patent DE102016115710.4A, 24 August 2016.

20. Kanemoto, T.; Oba, S. Proposition of unique pumping system with counter-rotating mechanism. Int. J. Rotating Mach. 2004, 10, 233-240. [CrossRef]

21. Ronald, H. Centrifugal Compressors: A Strategy for Aerodynamic Design and Analysis; AMSE Press: New York, NY, USA, 2000.

22. Asuaje, M.; Bakir, F.; Kouidri, S.; Noguera, R.; Rey, R. Computer-aided design and optimization of centrifugal pumps. Proc. Inst. Mech. Eng. Part J. Power Energy 2005, 219, 187-193. [CrossRef]

23. Robert, R.; Bakir, F.; Poulain, J. Pompes Rotodynamiques-Similitude et Conception des Pompes Centrifuges; Techniques de l'Ingénieur: Saint-Denis, France, 2012.

24. Chikh, M.A.A.; Belaidi, I.; Khelladi, S.; Deligant, M.; Bakir, F. Efficiency of bio- and socio-inspired optimization algorithms for axial turbomachinery design. Appl. Soft Comput. 2018, 64, 282-306. [CrossRef]

25. Chikh, M.A.A.; Belaidi, I.; Khelladi, S.; Hamrani, A.; Bakir, F. Coupling of inverse method and cuckoo search algorithm for multiobjective optimization design of an axial flow pump. Proc. Inst. Mech. Eng. Part J. Power Energy 2019, 233, 988-1006. [CrossRef]

26. Bourabia, L.; Abed, C.B.; Cerdoun, M.; Khalfallah, S.; Deligant, M.; Khelladi, S.; Chettibi, T. Aerodynamic preliminary design optimization of a centrifugal compressor turbocharger based on a one-dimensional mean-line model. Eng. Comput. 2021. [CrossRef]

27. Balje, O. Turbomachines-A Guide to Design, Selection, and Theory; John Wiley \& Sons: Hoboken, NJ, USA, 1981.

28. Abed, C.B.; Khelladi, S.; Michael, D.; El Marjani, A.; Farid, B. Preliminary study of a centrifugal compressor with counter-rotating impellers: Design and performances study. In Proceedings of the ASME Turbo Expo 2020: Turbine Technical Conference and Exposition, Online, 21-25 September 2020.

29. Van den Braembussche, R. Thermodynamics and Fluid Mechanics of Turbomachinery; Martinus Nijhoff Publishers: Dordrecht, The Netherlands, 1985; pp. 829-885.

30. Japikse, D. Centrifugal Compressor Design and Performance; Concepts ETI: Vermont, VT, USA, 1996.

31. STAR-CCM+, U.G. Version 13.064. 2018. Available online: https://www.plm.automation.siemens.com/global/en/products/ simcenter/STAR-CCM.html (accessed on 10 January 2021).

32. Menter, F.R.; Kuntz, M.; Langtry, R. Ten years of industrial experience with the SST turbulence model. Turbul. Heat Mass Transf. 2003, 4, 625-632.

33. Gibson, L.; Galloway, L.; Kim, S.; Spence, S. Assessment of turbulence model predictions for a centrifugal compressor simulation. J. Glob. Power Propuls. Soc. 2017, 1, 142-156. [CrossRef]

34. Bourgeois, J.A.; Martinuzzi, R.J.; Savory, E.; Zhang, C.; Roberts, D.A. Assessment of turbulence model predictions for an aero-engine centrifugal compressor. J. Turbomach. 2011, 133. [CrossRef]

35. ISO. Turbocompressors_Performance Test Code—Simplified Acceptance Test; International Organization for Standardization: Vernier, Switzerland, 2016.

36. Valencia, E.; Granja, V.; Palacios, J.; Poveda, R.; Cando, E.; Hidalgo, V. Uncertainty analysis of a test-rig for centrifugal compressors. Rev. Politécnica 2015, 35, 19. 